\title{
A Further Study of Wave Disturbances in the Conditionally Unstable Model Tropics*
}

\author{
By Masanori Yamasaki** \\ New York University \\ (Manuscript received 20 April 1971)
}

\begin{abstract}
As a continuation of previous studies (Yamasaki, 1969; Ooyama, 1971), the properties of wave disturbances superimposed upon zonal current in a conditionally unstable model tropics are studied by solving linearized primitive equations on the spherical coordinates. The effect of moist convection is incorporated by the use of the assumption that non-adiabatic heating due to convective clouds is specified by the horizontal convergence in the boundary layer, as Ooyama (1964) proposed in the study of tropical cyclones.

In the absence of zonal current, surface friction and heat release, the model includes barotropic Rossby mode discussed by Haurwitz (1940b) in addition to baroclinic Rossby mode, gravity mode and Kelvin mode discussed by Matsuno (1966). It is found that the Haurwitz type waves of the lower meridional modes $(n=0,1)$ become unstable when surface friction, heat release and vertical shear of a zonal current are incorporated. The preferred wavelength increases from about $2,000 \mathrm{~km}$ to $6,000 \mathrm{~km}$ with the increase in vertical shear. Comparisons with observations show that the lowest meridional mode $(n=0)$ is similar to the equatorial easterly wave described by Palmer (1952) and that analyzed by Chang et al. (1970). Since frictional convergence is a maximum at latitudes where the absolute value of the Coriolis parameter is equal to the frequency of this wave relative to the basic zonal current (Holton et al., 1971; Yamasaki, 1971), the stability properties of this wave appears to be strongly controlled by heat release associated with the frictional convergence around this latitude.
\end{abstract}

The properties of other kinds of unstable waves are also discussed briefly.

\section{Introduction}

In recent years the importance of convective clouds on tropical disturbances (such as tropical cyclones and easterly waves) has been increasingly recognized. In particular, it has been established by many theoretical and observational studies that the interaction between deep cumulus clouds and tropical cyclones is an indispensable factor to the development and maintenance of tropical cyclones (Ooyama, 1964; Charney and Eliassen, 1964; Ogura, 1964 and others). On the other hand, the role of cumulus clouds on the easterly wave has not been fully recognized yet. This is

* Contribution No. 101, Geophysical Sciences Laboratory, Department of Meteorology and Oceanogräphy, New York University. This research has been supported by National Science Foundation under Grant GA-12568.

** Permanent affiliation: Meteorological Research Institute, Tokyo partly because the cold-cored structure which has been usually observed in the lower troposphere (Riehl, 1954; Yanai, 1961 and others) has suggested another kind of possible mechanism such as barotropic instability associated with the horizontal shear of the trade easterlies. Recently Nitta and Yanai (1969) and Lipps (1970) made preliminary studies along this line.

Manabe and Smagorinsky (1967) showed that tropical disturbances in their general circulation model were maintained by the eddy available potential energy produced by condensation heat. A cold core was confined to the lower troposphere and a warm core was obtained in the upper troposphere. Although this seemed to be the consequence of the adopted parameterization of convection, their study suggested the existence of a warm core in the upper troposphere of observed easterly waves. This suggestion has been supported by recent several observational studies (Yanai, 1968; Riehl, 1969; Nitta, 1970a; Chang et al., 
1970 and others).

Although the study of Manabe and Smagorinsky (1967) was significant one which suggested the importance of heat release by convective clouds in tropical disturbances, there still remained many questions as to the dynamics of tropical disturbances such as more detailed role of heat release, the importance of surface friction, those of vertical and horizontal shears of the trade easterlies and the properties (scale and structure) of wave disturbances thus induced. In order to answer these questions it appeared to be the easiest way to solve linearized equations which describe wave disturbances in a model tropics with parameterized convective effects.

In a previous paper (Yamasaki, 1969)* it was attempted to explain tropical wave disturbances by taking account of not only the conditionally unstable stratification of the tropical atmosphere and surface friction but also the vertical shear of the easterlies. The effect of the conditionally unstable stratification was incorporated in the same manner as Ooyama (1964) proposed in the study of tropical cyclone development; that is, the amount of heat released by convective clouds was assumed to be specified by the horizontal convergence in the friction layer. In such a model of the tropical atmosphere it was found that three kinds of unstable waves could exist in addition to the tropical cyclone. The first unstable wave referred to as Mode (ES) moves westward at a speed of low level easterlies, and its growth rate increases with increasing vertical shear. Although Mode (ES) becomes similar to the baroclinic unstable wave of the lowest vertical mode (Charney, 1947 and others) for very strong shear and weak heating, this mode for moderate intensity of the shear is quite different from the baroclinic wave with respect to the structure and the importance of heat release and surface friction. The second unstable wave referred to as Mode (E) moves westward faster than the easterly current, and becomes most unstable for moderate intensity of the shear. This mode is considered to be a kind of Rossby wave destabilized by released latent heat under the existance of the vertical shear and surface friction. The third unstable wave referred to as Mode (HB) is a Rossby wave destabilized mainly by released latent heat. In contrast to Mode (ES) and (E), vertical

\footnotetext{
* Hereafter referred to as paper Y.
}

shear of the easterlies is not an important factor to the growth of Mode (HB). Surface friction plays an essential role only when the amount of heat released in the upper troposphere is not large. When vertical shear is increased and the amount of heat is decreased, Mode (HB) is reduced to a baroclinic unstable wave of the second vertical mode. While the amount of heat released in the lower troposphere is a determining factor to the growth of the tropical cyclone (Syono and Yamasaki, 1966), the growth of these three modes (particularly Mode HB) is mainly determined by heat amount released in the upper troposphere. Which mode is most preferred among these four modes depends upon the vertical distribution of released heat, vertical shear of the easterlies and some other factors.

The stability of wave disturbances in the model tropics has been also discussed by Ooyama (1971). Besides many results common to those in paper $\mathrm{Y}$, some of the most significant results are that the pure baroclinic instability might be important also in the tropics and that the importance of the conditionally unstable stratification on the baroclinic unstable wave depends upon the vertical profile of the easterlies. When the vertical shear is absent or very weak in the lower troposphere, the amplitude of the baroclinic unstable wave is small around $900 \mathrm{mb}$ and therefore the wave is scarcely modified by heat release which is assumed to be proportional to the vertical motion at 900 $\mathrm{mb}$. When the vertical shear is strong around $900 \mathrm{mb}$, the wave could be greatly modified by heat release. It is this type of wave that is referred to as Mode (ES) in paper Y.

Although the validity of the adopted parameterization of cumulus convection may be somewhat doubtful, it appears that the model could simulate several characteristics of some phenomena observed in the tropical atmosphere. The horizontal scales of Mode (ES) and (E) take a range of 2,000 to $4,000 \mathrm{~km}$ which is comparable to the scale of the observed easterly wave (Riehl, 1954; Wallace and Chang, 1969; Chang, 1970 and others). The scale of Mode (HB) is also comparable to these values when the amount of heat released in the upper troposphere is not large. Because of some uncertainty of our knowledge as to the structure of the easterly wave it is not clear which mode is the most similar to the easterly wave. It was suggested that three kinds of easterly waves might exist in the tropical 
atmosphere. The study further showed that, when the amount of heat released in the upper troposphere is large, Mode (HB) becomes similar to the planetary-scale equatorial wave which was discovered by Yanai and Maruyama (1966) and described in subsequent papers (Maruyama, 1967, 1968a, b; Yanai et al., 1968; Yanai and Hayashi, 1969 and others).

It should be mentioned that the properties of these modes were discussed by the use of a twodimensional model where latitudinal variations of wave properties were ignored. Therefore, the growth rates of these modes were obtained as functions of the latitude. In view of the result that Mode (E) and (HB) become most unstable for very low latitudes, it was suggested that the properties of these two modes should be reexamined by a three-dimensional primitive equation model applied to the whole tropical atmosphere including the equator. The first attempt was made by Hayashi (1970). Using an equatorial $\beta$-plane model he studied wave properties for the case in which neither vertical shear of the easterlies nor surface friction exist. He showed that some of the Rossby waves discussed by Rosenthal (1965) and Matsuno (1966) are destabilized by heat release. The vertical structures of these unstable waves are quite similar to that of Mode (HB) and the heating conditions for the occurrence of these waves are exactly the same. Hayashi (1970) further showed that the wave named mixed Rossby-gravity wave by Matsuno (1966) becomes most unstable among various modes of Rossby waves and that this wave is strikingly similar to Yanai-Maruyama wave under some heating.

One of remaining interesting problems is to discuss the properties of Mode (E) by the use of a three-dimensional model. In the absence of the vertical shear, surface friction and heat release, in addition to Rossby waves discussed by Matsuno (1966) and others, we have another kind of Rossby waves which are not accompanied by vertical motions. The properties of this non-divergent Rossby mode were discussed by Rossby et al., (1939) and Haurwitz (1940a) with a $\beta$-plane model and by Haurwitz (1940b) with a spherical coordinate model. The primary objective of the present study is to show that this mode becomes unstable by condensation heat released in association with vertical motions which are caused by surface friction and vertical shear of the easterlies. This unstable wave corresponds to Mode (E).
Some discussions will be also made as to other types of unstable waves.

\section{Basic equations}

The model used in this study is almost the same as that used in paper $Y$ except that we discuss the problem by the use of a threedimensional model. Since the Rossby mode which we are most concerned with in this study is not usually trapped in the low latitudes, it is desirable to use the spherical coordinates $(\lambda, \varphi, p)$, where $\lambda$ is the longitude, $\varphi$ is the latitude and $p$ is the pressure taken as the vertical coordinate. Basic equations (including non-adiabatic heating due to small scale convection $Q$ and vertical eddy viscosity $F$ ) may be written as follows:

$$
\begin{aligned}
& \frac{\partial u}{\partial t}+u \frac{\partial u}{a \cos \varphi \partial \lambda}+v \frac{\partial u}{a \partial \varphi}+\omega \frac{\partial u}{\partial p} \\
&-\frac{u v \tan \varphi}{a}-2 \Omega \sin \varphi v \\
&=-\frac{1}{a \cos \varphi} \frac{\partial \phi}{\partial \lambda}+F_{\lambda} \\
& \frac{\partial v}{\partial t}+u \frac{\partial v}{a \cos \varphi \partial \lambda}+v \frac{\partial v}{a \partial \varphi}+\omega \frac{\partial v}{\partial p} \\
&+\frac{u^{2} \tan \varphi}{a}+2 \Omega \sin \varphi u \\
&=-\frac{1}{a} \frac{\partial \phi}{\partial \varphi}+F_{\varphi} \\
& \frac{\partial \theta}{\partial t}+u \frac{\partial \theta}{a \cos \varphi \partial \lambda}+v \frac{\partial \theta}{a \partial \varphi}+\omega \frac{\partial \theta}{\partial p}=\frac{1}{C_{p} \Pi} Q \\
& \frac{\partial \phi}{\partial p}=-\frac{R \Pi}{p} \theta \\
& \frac{1}{a \cos \varphi}\left[\frac{\partial u}{\partial \lambda}+\frac{\partial(v \cos \varphi)}{\partial \varphi}\right]+\frac{\partial \omega}{\partial p}=0
\end{aligned}
$$

The five dependent variables are $u=$ zonal wind component, $v=$ meridional wind component, $\omega=$ vertical $p$-velocity, $\theta=$ potential temperature and $\phi=$ geopotential of isobaric surfaces. Other notations are $t=$ time, $a=$ radius of the earth $\Omega=$ angular velocity of the earth's rotation, $R=$ gas constant of dry air, $C_{p}=$ specific heat at constant pressure, $\Pi=\left(p / p_{0}\right)^{R / C_{p}}, p_{0}$ is the reference pressure taken as $1,000 \mathrm{mb}, Q=$ heating per 
unit mass per unit time, $F_{\lambda}$ and $F_{\varphi}=$ frictional forces.

The effect of cumulus convection in the conditionally unstable tropical atmosphere will be taken into account by the use of the same method as that used in the previous study. That is,

$$
Q=-C_{p} \Pi \operatorname{sh} \omega_{900}
$$

where $s=-\partial \theta / \partial p, \omega_{900}$ is the vertical $p$-velocity at $900 \mathrm{mb}$, and $h$ is a non-dimensional parameter concerning the intensity of heating. The assumption (2.6) is essentially the same as that proposed by Ooyama (1964) in the study of tropical cyclone development. In this study $h$ will be treated as a parameter which is a function of $p$ and $\varphi$.

The frictional forces due to the vertical eddy viscosity are assumed in a usual way as follows:

$$
\begin{aligned}
& \left.\begin{array}{l}
F_{\lambda}=-g \frac{\partial \tau_{\lambda}}{\partial p} \\
F_{\varphi}=-g \frac{\partial \tau_{\varphi}}{\partial p}
\end{array}\right\} \\
& \tau_{\lambda}= \begin{cases}0 & \left(p=p_{T}\right) \\
-\rho^{2} g K \frac{\partial u}{\partial p} & \left(p_{T}<p<p_{S}\right) \\
\rho C_{D}|V| u & \left(p=p_{S}\right)\end{cases} \\
& \tau_{\varphi}= \begin{cases}0 & \left(p=p_{T}\right) \\
-\rho^{2} g K \frac{\partial v}{\partial p} & \left(p_{T}<p<p_{S}\right) \\
\rho C_{D}|V| v & \left(p=p_{S}\right)\end{cases}
\end{aligned}
$$

where $K$ is the coefficient of the vertical eddy viscosity, $C_{D}$ the drag coefficient, $g$ the acceleration of gravity, $\rho$ density, and $|V|=\left(u^{2}+v^{2}\right)^{1 / 2}$. $p_{T}$ and $p_{S}$ are the pressures of the upper and lower boundaries of the atmosphere under consideration, respectively.

We shall discuss the stability of small amplitude wave disturbances superimposed upon a basic state, which satisfies the following:

(1) The basic flow is zonal, and its angular velocity $\alpha$ is a function of $\varphi$ and $p$.

$$
U=\alpha(\varphi, p) a \cos \varphi
$$

We shall limit our discussions to the case where $\alpha$ is symmetric with respect to the equator.

(2) The basic state is in geostrophic and hydrostatic balances.

$$
\begin{aligned}
& \frac{\partial \phi_{0}}{\partial \partial \varphi}=-\left[U^{2} \tan \varphi / a+2 \Omega \sin \varphi U\right] \\
& \frac{\partial \phi_{0}}{\partial \lambda}=0 \\
& \frac{\partial \phi_{0}}{\partial p}=-\frac{R \Pi}{p} \theta_{0}
\end{aligned}
$$

where $\phi_{0}$ and $\theta_{0}$ are geopotential and potential temperature of the basic state, respectively.

(3) The basic state is statically stable. We shall define dry static stability of the basic state by

$$
S \equiv-\partial \theta_{0} / \partial p>0
$$

Since we can assume that solutions of linearized perturbation equations take the form of $\widetilde{A}(\varphi, p) \exp i(\nu t+l \lambda)$, a set of equations for the amplitudes of a perturbation may be written as follows:

$$
\begin{gathered}
i(\nu+l \alpha) \tilde{u}+\left[\cos \varphi \frac{\partial \alpha}{\partial \varphi}-2 \sin \varphi(\Omega+\alpha)\right] \tilde{v} \\
+a \cos \varphi \frac{\partial \alpha}{\partial p} \tilde{\omega}+\frac{i l}{a \cos \varphi} \tilde{\phi}-\bar{F}_{\lambda}=0 \\
i(\nu+l \alpha) \tilde{v}+2 \sin \varphi(\Omega+\alpha) \tilde{u}+\frac{\partial \tilde{\phi}}{a \partial \varphi}-\bar{F}_{\varphi}=0 \\
i(\nu+l \alpha) \tilde{\theta}+\frac{\partial \theta_{0}}{a \partial \varphi} \tilde{v}-S \tilde{\omega}+h \tilde{S}_{900}=0 \\
\frac{\partial \tilde{\phi}}{\partial p}+\frac{R \Pi}{p} \widetilde{\theta}=0 \\
i l \tilde{u}+\frac{\partial(\tilde{v} \cos \varphi)}{\partial \varphi}+a \cos \varphi \frac{\partial \tilde{\omega}}{\partial p}=0
\end{gathered}
$$

where

$$
\frac{\partial \theta_{0}}{a \partial \varphi}=\frac{p}{R I} \frac{\partial}{\partial p}\left[U^{2} \tan \varphi / a+2 \Omega \sin \varphi U\right]
$$

The wavy symbol denotes the complex amplitude of perturbations, $l$ is the wavenumber in the zonal direction and $\nu_{r}$, the real part of $\nu$, is the frequency. The growth rate is given by $q=-\operatorname{Im}(\nu)$. The thermal wind relation (2.16) is derived from (2.9). $\bar{F}_{\lambda}$ and $\bar{F}_{\varphi}$ in (2.11) and (2.12) may be expressed in the same form as (2.7a) and (2.7b) except that $\rho$ is replaced by $\rho_{0}\left(\equiv p / R \Pi \theta_{0}\right), u$ by $\tilde{u}, v$ by $\tilde{v}$ and $|V|$ is considered 
to be a constant. When we obtain (2.11)-(2.15) we have neglected frictional terms due to basic current. Now our problem is to obtain $\nu$ and the five amplitude functions from a set of equations (2.11)-(2.15) by imposing the boundary conditions

$$
\begin{aligned}
& \tilde{v}=0 \text { at } \varphi= \pm \varphi_{B} \\
& \tilde{\boldsymbol{\omega}}=0 \text { at } p=p_{S} \text { and } p_{T}
\end{aligned}
$$

where $\varphi_{B}$ is the latitude of lateral boundaries. The specification of various parameters $\alpha(\varphi, p)$, $h(\varphi, p), S(0, p), K(p), C_{D}|V|, \varphi_{B}, p_{S}, p_{T}$ and $l$ will be made later.

\section{Five-layer model}

In order to solve equations (2.11)-(2.15) numerically, we shall use a five-layer model, which is shown in Fig. 1. The variables $u, v$ and $\phi$ are defined at five layers. The lower two

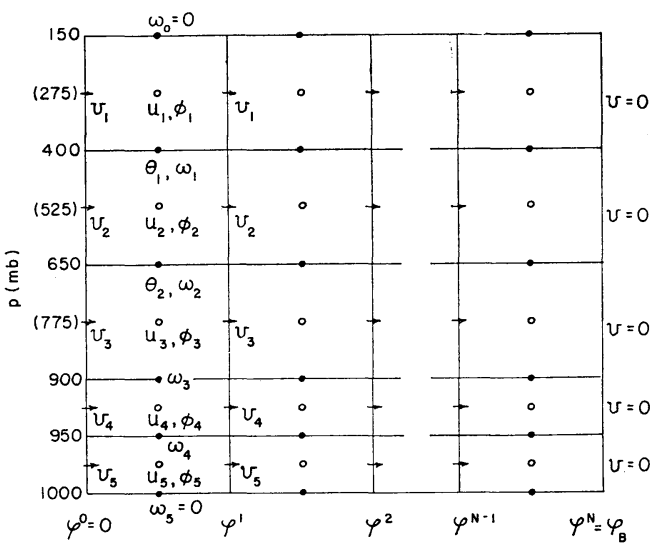

Fig. 1. A five-layer model.

layers may be considered as the boundary layer. As for the latitudinal direction, $v$ is defined at different latitudes from those of $u, \phi, \omega$ and $\theta$. Since we consider a zonal flow which is symmetric with respect to the equator, solutions are such that either $v$ is symmetric with respect to the equator and the other fields are antisymmetric or $v$ is antisymmetric and the others are symmetric. Taking account of this property, it is sufficient to consider the northern hemisphere only.

The thermodynamic equation (2.13) is applied at $400 \mathrm{mb}$ and $650 \mathrm{mb}$. The static stability $S_{j}(j=1,2)$ are assumed to be $0.07 \mathrm{~K} \mathrm{mb}^{-1}$ over the equator, where subscript $j$ refers to the level. The heating parameter $h$ is assumed to be of the following form:

$$
h= \begin{cases}\eta \zeta^{i} & \text { at } 400 \mathrm{mb} \\ \xi \zeta^{i} & \text { at } 650 \mathrm{mb}\end{cases}
$$

where $\eta$ and $\xi$ are constant parameters concerning the intensity of heating, and $\zeta^{i}(i=1,2, \cdots \cdots, N)$ represents the latitudinal profile of $h$, which are defined at $\varphi=\left(\varphi^{i}+\varphi^{i-1}\right) / 2$, where superscript $i$ refers to latitude. A maximum value of $\zeta$ is taken to be unity. It is assumed that the perturbation potential temperature vanishes at $900 \mathrm{mb}$ and $950 \mathrm{mb}$. Similar assumption was used in studies of tropical cyclones (Ooyama, 1969; Yamasaki, 1968a, b, c) and also in paper Y. Under this assumption, $\phi_{4}$ and $\phi_{5}$ are equal to $\phi_{3}$, while $\phi_{1}, \phi_{2}$ and $\phi_{3}$ are related through the hydrostatic equation (2.14). The continuity equation (2.15) and the equation of motion (2.11) are applied at the grids where $u$ is defined. The equation of motion (2.12) is applied at the grids of $v$.

The angular velocity of a zonal current $\alpha$ is taken to be of the following form:

$$
\begin{aligned}
& \alpha= \begin{cases}0 & \text { at } 275 \mathrm{mb} \\
\alpha_{s} / 2 & \text { at } 525 \mathrm{mb} \\
\alpha_{s} & \text { at } 775 \mathrm{mb}, 925 \mathrm{mb} \text { and } 975 \mathrm{mb}\end{cases} \\
& \alpha_{s}=-\frac{\Lambda}{a \cos \varphi_{M}} \alpha_{y}
\end{aligned}
$$

where $\Lambda$ is a maximum intensity of an easterly current and $\varphi_{M}$ is a latitude where $\alpha_{y} \cos \varphi$ is a maximum. In this study we consider three types of horizonal profiles as follows:

$$
\begin{aligned}
& \left\{\begin{array}{ll}
\cos ^{2}\left(\pi \varphi / 2 \varphi_{0}\right) & \left(|\varphi|<\varphi_{0}\right) \\
0 & \left(|\varphi|>\varphi_{0}\right)
\end{array}\right\} \text { (Profile E1) }
\end{aligned}
$$

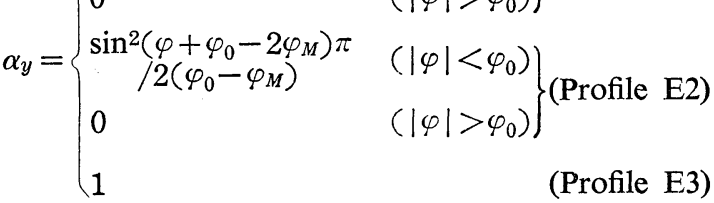

where $\varphi_{0}$ is a latitude where a zonal current vanishes for Profile (E1) and (E2). Profile (E1) is such that a maximum easterly current is located at the equator. In Profile (E2) two maxima of an easterly current are located at $\pm \varphi_{M}$ and the profile is of double jet type. It may be more 
interesting to consider a single jet whose center is located only at $\varphi_{M}$. However, this case will not be discussed. The frictional terms may be expressed as follows:

$$
\begin{array}{r}
\bar{F}_{\lambda j}=\left\{\begin{array}{lc}
a_{1}\left(u_{2}-u_{1}\right) & (j=1) \\
a_{j}\left(u_{j+1}-u_{j}\right)+b_{j}\left(u_{j-1}-u_{j}\right) & (j=2,3,4) \\
-D u_{5}+b_{5}\left(u_{4}-u_{5}\right) & (j=5)
\end{array}\right. \\
\left\{\begin{array}{cc}
a_{j}=\left(\frac{g p}{R \Pi \theta_{0}}\right)_{j}^{2} \frac{2 K_{j}}{\left[(\Delta p)_{j}+(\Delta p)_{j+1}\right](\Delta p)_{j}} & (j=1,2,3,4) \\
b_{j}=\left(\frac{g p}{R \Pi \theta_{0}}\right)_{j}^{2} \frac{2 K_{j-1}}{\left[(\Delta p)_{j}+(\Delta p)_{j-1}\right](\Delta p)_{j}} \\
(j=2,3,4,5) \\
D=C_{D}|V|\left(g p / R \Pi \theta_{0}\right)_{5} /(\Delta p)_{5}
\end{array}\right.
\end{array}
$$

where the coefficient of the vertical eddy viscosity $K_{j}(j=1,2,3,4)$ are defined at $400,650,900$ and $950 \mathrm{mb}$, and $(\Delta p)_{1}=(\Delta p)_{2}=(\Delta p)_{3}=250 \mathrm{mb}$ and $(\Delta p)_{4}=(\Delta p)_{5}=50 \mathrm{mb}$. When we take $C_{D}|V|$ $=0.005$, the value of $D$ is nearly equal to $10^{-5}$ $\sec ^{-1}$. Similar expressions hold for $\bar{F}_{\varphi j}$.

Preliminary calculations have shown that a notable computational mode appears in the fields of $u_{4}, u_{5}, v_{4}, v_{5}$ and $\omega_{3}$ when surface friction is incorporated. This arises from the finite difference scheme in which the Coriolis terms are represented by the average of the values at two grid points since $u$ and $v$ are defined at different latitudes. (At high altitudes no notable conputational mode was found because of the suppression by stable stratification and weak influence of surface friction). In order to avoid such a computational mode a special treatment is used for the equations for $u_{4}^{i}, u_{5}^{i}, v_{4}^{i-1}$ and $v_{5}^{i-1}(i=1,2 \cdots \cdots, N)$, where $i$ for $u$ and $v$ refers to different latitudes. When we obtain equations for $u_{4}$ and $u_{5}$ (superscript $i$ is omitted), equation (2.11) is applied at the grids of $u_{3}, u_{4}$ and $u_{5}$. By using the assumption $\phi_{3}=\phi_{4}=\phi_{5}$, we have two equations as follows:

$$
\begin{aligned}
& \left(i \nu+i l \alpha_{s}\right) u_{5}-f_{1} v_{5}^{*}+D u_{5}-b_{5}\left(u_{4}-u_{5}\right) \\
= & \left(i \nu+i l \alpha_{s}\right) u_{4}-f_{1} v_{4}^{*}-a_{4}\left(u_{5}-u_{4}\right)-b_{4}\left(u_{3}-u_{4}\right) \\
= & \left(i \nu+i l \alpha_{s}\right) u_{3}-f_{1} v_{3}^{*}+a \cos \varphi(\partial \alpha / \partial p)_{3}\left(\omega_{2}+\omega_{3}\right) \\
& / 2-a_{3}\left(u_{4}-u_{3}\right)-b_{3}\left(u_{2}-u_{3}\right)
\end{aligned}
$$

where $v_{3}^{*}, v_{4}^{*}$ and $v_{5}{ }^{*}$ may be regarded as $v$ at the grids of $u_{3}, u_{4}$ and $u_{5}$, respectively (not defined explicitly in Fig. 1) and $f_{1} \equiv 2 \sin \varphi(\Omega+\alpha)-\cos$ $\varphi \partial \alpha / \partial \varphi$. Equation (2.12) is also applied at the same grids. Then we have

$$
\begin{aligned}
& \left(i \nu+i l \alpha_{s}\right) v_{5}^{*}+f_{2} u_{5}+D v_{5}^{*}-b_{5}\left(v_{4}^{*}-v_{5}^{*}\right) \\
= & \left(i \nu+i l \alpha_{s}\right) v_{4}^{*}+f_{2} u_{4}-a_{4}\left(v_{5}^{*}-v_{4}^{*}\right)-b_{4}\left(v_{3}^{*}-v_{4}^{*}\right) \\
= & \left(i \nu+i l \alpha_{s}\right) v_{3}^{*}+f_{2} u_{3}-a_{3}\left(v_{4}^{*}-v_{3}^{*}\right)-b_{3}\left(v_{2}^{*}-v_{3}^{*}\right)
\end{aligned}
$$

where $f_{2} \equiv 2 \sin \varphi(\Omega+\alpha)$. Eliminating $v_{4}{ }^{*}$ and $v_{5} *$ from (3.4a) and (3.4b) we obtain two linear equations in which $u_{4}$ and $u_{5}$ are related to $u_{2}$, $u_{3}, \omega_{2}, \omega_{3}, v_{2}^{*}$ and $v_{3}^{*}$.

$$
\begin{aligned}
& u_{4}^{i}=F_{1}\left(u_{2}^{i}, u_{3}^{i}, \omega_{2}^{i}, \omega_{3}^{i}, v_{2}{ }^{*}, v_{3}{ }^{*}\right) \\
& u_{5}^{i}=F_{2}\left(u_{2}^{i}, u_{3} i, \omega_{2}^{i}, \omega_{3}{ }^{2}, v_{2}{ }^{*}, v_{3}{ }^{*}\right)
\end{aligned}
$$

where

$$
v^{*}=\left(v^{i}+v^{i-1}\right) / 2 .
$$

When we determine $v_{4}$ and $v_{5},(2.11)$ and (2.12) are applied at the grids of $v_{3}, v_{4}$ and $v_{5}$. Four equations are obtained by replacing $u_{j}$ by $u_{j}^{*}$, $v_{j}^{*}$ by $v_{j}(j=2,3,4,5)$ and $\omega_{j}$ by $\omega_{j}^{*}(j=2,3)$ in (3.4a) and (3.4b). Eliminating $u_{4}{ }^{*}$ and $u_{5}{ }^{*}$ we have linear equations in which $v_{4}$ and $v_{5}$ are related to $v_{2}, v_{3}, u_{2}{ }^{*}, u_{3}{ }^{*}, \omega_{2}{ }^{*}$ and $\omega_{3}{ }^{*}$.

$$
\begin{aligned}
& v_{4}{ }^{i}=F_{3}\left(v_{2}{ }^{i}, v_{3}{ }^{i}, u_{2}{ }^{*}, u_{3}{ }^{*}, \omega_{2}{ }^{*}, \omega_{3}{ }^{*}\right) \\
& v_{5}{ }^{i}=F_{4}\left(v_{2}{ }^{i}, v_{3}{ }^{i}, u_{2}{ }^{*}, u_{3}{ }^{*}, \omega_{2}{ }^{*}, \omega_{3}{ }^{*}\right)
\end{aligned}
$$

where

$$
u^{*}=\left(u^{i}+u^{i+1}\right) / 2 \text { and } \omega^{*}=\left(\omega^{i}+\omega^{2+1}\right) / 2 .
$$

Equations (3.5a) and (3.5b) include $\nu$. In this study $\nu$ in these equations is replaced by a prescribed constant $\nu_{0}$. It has been found that slight difference between $\nu_{0}$ and a solution $\nu$ makes little difference for results. If we desire to obtain more precise solutions, iterations can be made by changing the value of $\nu_{0}$.

Finite difference equations which are derived by applying equations (2.11)-(2.15) to the fivelayer model in the way mentioned above form a set of linear algebraic homogeneous equations. It is easy to eliminate $\theta_{1}{ }^{i}, \theta_{2}{ }^{i}$ and $\omega_{4}{ }^{i}$. After this elimination resulting equations can be written in the form

$$
(E)(\chi)=0
$$

where $(E)$ is a square matrix of $16 \mathrm{~N}$ degrees for the $v$-symmetric mode and $(16 \mathrm{~N}-5)$ degrees for the $v$-antisymmetric mode, where $\mathrm{N}$ is the number 
of the grid in the horizontal direction. $(\chi)$ is a vector consisting of the dependent variables. The frequency $\nu$ can be obtained from the condition

$$
\operatorname{Det}(E)=0
$$

The number of solutions is $7 \mathrm{~N}$ for the $v$-symmetric mode and (7N-3) for the $v$-antisymmetric mode; that is, we have $(14 \mathrm{~N}-3)$ solutions in the present model.

When a zonal current, friction and heat release are absent, (6N-3) solutions correspond to Rossby waves, $(8 \mathrm{~N}-6)$ solutions to gravity waves and 2 solutions to Kelvin waves. Remaining 4 solutions are false ones which do not correspond to any solutions of the differential equations (2.11)(2.15). The solutions corresponding to Rossby waves are further classified into two types. (2N-1) solutions represent non-divergent (barotropic) Rossby waves discussed by Haurwitz (1940b) and (4N-2) solutions represent divergent (baroclinic) Rossby waves discussed by Matsuno (1966). The analytical solution of the non-divergent Rossby wave may be, following Haurwitz (1940b), written as follows:

$$
\begin{aligned}
& \tilde{\omega}=\tilde{\theta}=0 \\
& \tilde{u}=-\partial \widetilde{\psi} / a \partial \varphi \\
& \tilde{v}=i l \tilde{\psi} / a \cos \varphi \\
& \tilde{\psi}=C P_{l+n}(\sin \varphi) \quad(n=0,1,2, \cdots \cdots) \\
& \nu=\frac{2 \Omega l \quad}{(n+l)(n+l+1)}
\end{aligned}
$$

where $\phi$ is the streamfunction, $C$ is a constant, $P$ is an associated Legendre polynomial and $n$ denotes the meridional mode. As mentioned in Section 1 , the primary objective of the present study is to show that Rossby waves of this type become unstable when surface friction, vertical shear of a zonal current and heat release are incorporated. For convenience we shall refer to this type of Rossby wave as mode $m=0$. The properties of Mode $(m=0, n=0)$ will be discussed in Section 4 and those of Mode $(m=0, n=1)$ in Section 5. Higher meridional modes will not be discussed.

The properties of the other type of Rossby waves are quite dependent upon the artificial upper and lower boundary conditions (2.17b).
When these Rossby waves become unstable, they may be regarded as waves for which the boundary condition (2.17b) is valid, as mentioned by Hayashi (1970). Among infinite number of different vertical modes only two vertical modes are described by the five-layer model used in this study. The lower vertical mode in which the phase difference between $\phi$ in the upper troposphere and $\phi$ in the lower troposphere is about $\pi$ may be the most interesting wave among various vertical modes (paper $\mathrm{Y}$; Hayashi, 1970). In this paper the lower vertical mode is referred to as mode $m=1$. The lowest meridional mode $n=0$ which is called "mixed Rossby-gravity wave" will be referred to as Mode $(m=1, n=0)$ and the second meridional mode as Mode $(m=1, n=1)$. The properties of these modes in the presence of heat release were discussed by Hayashi (1970). The effects of friction and vertical shear on these modes will be briefly discussed in Section 6 .

Physical parameters which appear in the present model are $\alpha_{y}, \Lambda, \varphi_{0}, \eta, \xi, \zeta^{i}(i=1,2, \cdots \cdots N), D$, $K_{j}(j=1,2,3,4)$ and $l$. In addition to these physical parameters we have two parameters $N$ and $\varphi_{B}$ which specify the grid points in the latitudinal direction and the latitude of lateral boundaries. A maximum value of $N$ which is possible at present for the author to use is 7 . For this value of $N, \varphi_{B}=42$ is used in this study. As is clear from the latitudinal profile of the amplitude of $v$ in Mode $(m=1, n=0)$ and Mode $(m=1, n=1)$ (Matsuno, 1966), this value of $\varphi_{B}$ is sufficiently large for these modes. As for mode $m=0$, the ratio of the amplitude of $v$ at $42 \mathrm{~N}$ to maximum amplitude is about 0.15 for $l=8$ of Mode $(m=0, n=0)$ and about 0.45 for $l=8$ of Mode $(m=0, n=1)$. (This ratio decreases with increasing wavenumber). When the middle latitude westerlies and the low latitude easterlies exist, as in the actual atmosphere, this ratio becomes surprisingly small (Yamasaki, unpublished work). Although the existence of the middle latitude westerlies and that of the lateral boundary do not have equivalent effects on wave properties, it may be safely said that the above value of $\varphi_{B}$ is not serious even for Mode $(m=0, n=1)$. In particular, when $A$ is large, this boundary condition may be quite justified. For these values of $N$ and $\varphi_{B}$, the grid size $\Delta \varphi$ is 6 degrees. For the save of computational time, $N=6$ and $\varphi_{B}=36$ will be often used for the discussion of Mode $(m=0$, $n=0$ ). 


\section{Mode $(m=0, n=0)$}

\subsection{Condition for instability}

Since mode $m=0$ corresponds to a wave which was referred to as Mode (E) in a two-dimensional model in paper $\mathrm{Y}$, the condition for instability of Mode $(m=0, n=0)$ is essentially the same as that for Mode (E). Surface friction and vertical shear of a zonal current as well as heat release are indispensable factors to the instability of this mode.

The heating condition for instability (not shown) is qualitatively similar to Fig. 21a of paper $Y$. That is, larger values of $\xi\left(h_{2}\right.$ in paper $\left.\mathrm{Y}\right)$ and $\eta\left(h_{3}\right)$ are favorable conditions for instability. The growth rate increases with increasing $\xi$ and $\eta$. Quantitatively, however, there is a significant difference in the $\xi-\eta$ diagram. The wave in the present model is much less unstable than in the previous model for given values of $\xi$ and $\eta$. This difference comes primarily from the difference of the models as follows. In paper $\mathrm{Y}$ it was assumed that heat was released in the layer of $700 \mathrm{mb}$ depth. In the present model the depth is assumed to be $500 \mathrm{mb}(275-775 \mathrm{mb})$. Therefore, from the standpoint of the amount of condensed water vapor, $(\xi=1.0, \eta=4.0)$ in the present model corresponds to $(\xi=1.0, \eta=2.5)$ in paper Y. In most of the following discussions of mode $m=0,(\xi=1.0, \eta=4.0)$ will be used.

The vertical shear of a zonal current is not

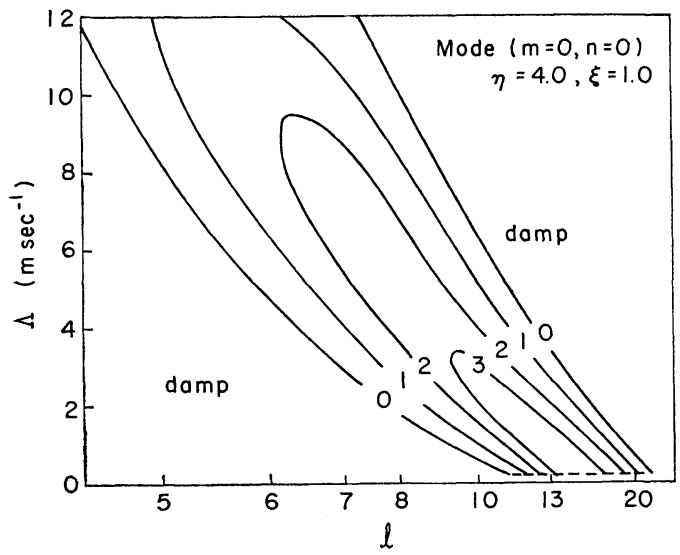

Fig. 2. Growth rates (unit: $10^{-7} \mathrm{sec}^{-1}$ ) of Mode ( $m=0, n=0$ ) as a function of $\Lambda$ and $l$. Other parameters are $\alpha_{y}=(\mathrm{E} 1), \varphi_{0}=35$, $\eta=4, \quad \xi=1, \quad \zeta=(\mathrm{H} 2) \quad$ (see Table 1), $D=10^{-5} \mathrm{sec}^{-1}, K_{1}=K_{2}=0$ and $K_{3}=K_{4}$ $=10 \mathrm{~m}^{2} \mathrm{sec}^{-1}$. only an indispensable factor to the instability of mode $m=0$ but also a determining factor to the wavenumber for which mode $m=0$ becomes unstable. Fig. 2 shows the condition for instability and the growth rate as a function of $A$ and $l$. The growth rate is given by numerals with a unit of $10^{-7} \mathrm{sec}^{-1}$. The values of parameters used are $N=6, \quad \varphi_{B}=36, \quad \xi=1.0, \quad \eta=4.0, \quad \zeta^{1}=\zeta^{2}=\zeta^{3}=1$, $\zeta^{4}=2 / 3, \zeta^{5}=1 / 3, \zeta^{6}=0, D=10^{-5} \mathrm{sec}^{-1}, K_{1}=K_{2}=0$, $K_{3}=K_{4}=10 \mathrm{~m}^{2} \mathrm{sec}^{-1}, \varphi_{0}=35$, and Profile (El) is taken. It is seen from this figure that the preferred wavenumber decreases from 15 to 6 with increasing vertical shear. (This preferred wavenumber probably becomes larger when vertical resolution of the finite difference is increased. This possibility is demonstrated in paper Y.) For a given wavenumber the wave is unstable between two critical shears and it becomes most unstable for a certain intensity of the shear. For larger wavenumber (11-20), this type of unstable waves are connected with a different type of unstable waves $(m=1)$ at very small $\Lambda$. The boundary between the two regimes is indicated by the chain line. These results are qualitatively the same as those obtained in paper Y. (In Fig. 20a in that paper, a chain line is missing by mistake).

An interesting result which was not discussed in paper $Y$ is found in the dependency of the stability properties on the latitudinal profiles of heat release and zonal current. We consider nine cases which consist of the combinations of three profiles of $h(y)$ and three profiles of $\alpha_{y}$. Heating $\mathrm{Hl}$ in Table 1 refers to the case where $h$ is independent of latitude. Heating $\mathrm{H} 2$ is the same as that used before. In Heating $\mathrm{H} 3$ heat release is assumed to be small in very low latitudes. The values of $\zeta^{i}$ are given in this table. The preferred wavenumber and its growth rate for the nine cases are shown in the right part

Table 1. Preferred wavenumbers and their growth rates $\left(10^{-6} \mathrm{sec}^{-1}\right)$ of Mode $(m=0, n=0)$ for nine combinations of latitudinal profiles of heat release and zonal current.

\begin{tabular}{ccccccc||ccc}
\hline & & & & & & & \multicolumn{4}{|c}{$\alpha_{y}$} \\
\hline & $\zeta^{1}$ & $\zeta^{2}$ & $\zeta^{3}$ & $\zeta^{4}$ & $\zeta^{5}$ & $\zeta^{6}$ & E1 & E2 & E3 \\
\hline H1 & 1 & 1 & 1 & 1 & 1 & 1 & $0.28(8)$ & $0.74(11)$ & $0.38(8)$ \\
\hline H2 & 1 & 1 & 1 & $2 / 3$ & $1 / 3$ & 0 & $0.25(8)$ & $0.61(10)$ & $0.34(8)$ \\
\hline H3 & 0 & $1 / 3$ & $2 / 3$ & 1 & 1 & 1 & damp & damp & damp \\
\hline
\end{tabular}


of this table. The unit of the growth rate is $10^{-6} \mathrm{sec}^{-1}$. We take $\Lambda=5 \mathrm{~m} \mathrm{sec}^{-1}$. Other paramterse are the same as those used before. This table demonstrates that heat release in very low latitudes $(\varphi<18 \mathrm{~N}$ in this case) is an important factor to the growth of Mode $(m=0$, $n=0$ ) and that the growth rate is primarily determined by heat release in this region. Table 1 also indicates that the wave is most unstable for wind profile (E2) and lest unstable for (E1). These results suggest that moderate intensity of the vertical shear at some distance from the equator and no or very weak shear near the equator produce favorable conditions for instability of Mode $(m=0, n=0)$. An interpretation of this result will be mentioned later. We can also see from this table that the preferred wavenumber is larger for Profile (E2) than for the other profiles.

In the following we shall see how the growth rate is dependent upon the coefficient of friction $D$ and $K_{j}$. This is shown in Fig. 3 where the

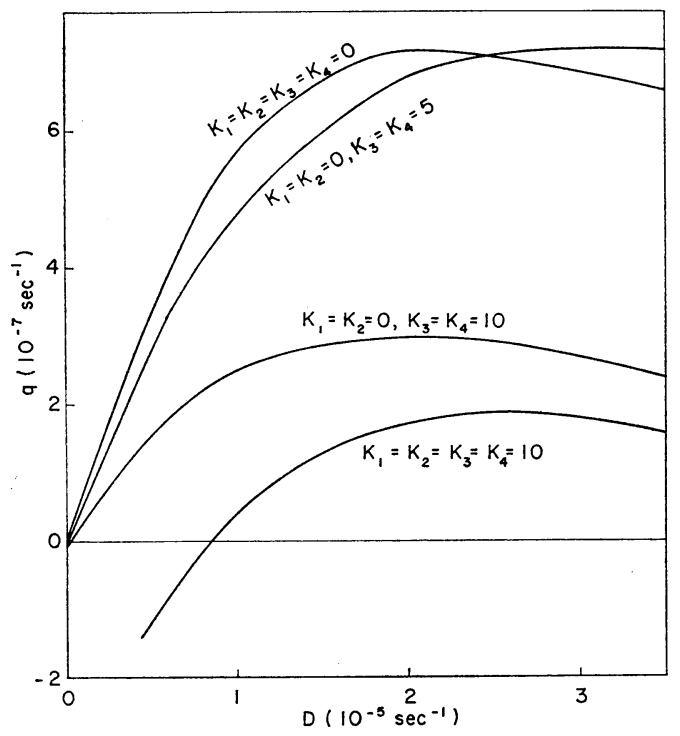

Fig. 3. Growth rates of Mode $(m=0, n=0)$ as functions of $D$ for four different values of $K_{j}$. Other parameters are $\alpha_{y}=(\mathrm{E} 1)$, $\varphi_{0}=35, \Lambda=5 \mathrm{~m} \mathrm{sec}^{-1}, \eta=4, \xi=1, \zeta=(\mathrm{H} 2)$ and $l=8$.

abscissa is the value of $D$. Four cases are shown by changing $K_{j}$. We take Profile (El) and $\Lambda=5 \mathrm{~m}$ $\mathrm{sec}^{-1}$. Since the preferred wavenumber of this mode in the case of $\Lambda=5 \mathrm{~m} \mathrm{sec}^{-1}$ is scarcely affected by the coefficient of surface friction, we take $l=8$ for all values of $D$ and $K_{j}$ under consideration. This figure indicates that the growth rate is a maximum when $D$ is nearly equal to $2-3 \times 10^{-5} \mathrm{sec}^{-1}$ and it gradually decreases for further increase in $D$. A maximum growth rate is found when $K_{3}$ and $K_{4}$ are somewhere between 0 and $5 \mathrm{~m}^{2} \mathrm{sec}^{-1}$. When both $K_{j}$ and $D$ are zero, the wave is exactly neutral. The existence of surface friction is indispensable to the growth of this wave.

\subsection{Frequency and period}

The frequency of mode $m=0$ in the case of $\Lambda=h=D=K_{j}=0$ is given by (3.8). Mode ( $m=0$, $n=0)$ is a wave which propagates westward faster than any other Rossby waves (including mixed Rossby-gravity wave). The period is about 7 days for $l=13,5.5$ days for $l=10,4.5$ days for $l=8$ and 3 days for $l=5$. When an easterly current exists, these periods become smaller particularly for larger wavenumbers. As for the period of the preferred wavenumber, it decreases from about 5 days to 3.5 days as $A$ increases from 2 to $10 \mathrm{~m}$ $\sec ^{-1}$.

\subsection{Vertical structure}

The vertical structure of Mode $(m=0, n=0)$ at $\varphi=15 \mathrm{~N}$ are shown in Figs. 4a-4d. In order to understand the effects of heat release and vertical shear of a zonal current, four cases are illustrated. The values of $\xi, \eta$ and $\Lambda$ are shown in the upper right in each figure. Figs. $4 \mathrm{c}$ and $4 \mathrm{~d}$ are adiabatic cases and Figs. $4 \mathrm{~b}$ and $4 \mathrm{~d}$ are non-shear cases. Other parameters used are $N=7, \varphi_{B}=42$, $\alpha_{y}=(\mathrm{E} 1), \varphi_{0}=35, \zeta^{i}=(\mathrm{H} 2), D=10^{-5} \mathrm{sec}^{-1}, K_{1}=K_{2}$ $=0, K_{3}=K_{4}=10 \mathrm{~m}^{2} \mathrm{sec}^{-1}$ and $l=8$. Only the first case (Fig. 4a) is the unstable case and the other three cases (Figs. 4b, 4c, 4d) are the damped case. The axis of the trough and ridge are indicated by the thick solid lines with $L$ and $H$, respectively. The arrows directed upward and downward indicate the location of the maximum and minimum vertical motions at 400, 650 and $900 \mathrm{mb}$. The arrows directed to right and left indicate the location of the maximum and minimum zonal wind component. The symbols $W$ and $C$ denote the locations of warm and cold regions. The numerals indicate the amplitude. The maximum amplitude of $v$ is chosen to be $1 \mathrm{~m} \mathrm{sec}^{-1}$. The unit of the $\omega$-amplitude is $10^{-3} \mathrm{mb}$ $\sec ^{-1}$.

It is found from these figures that the significant effects of the vertical shear $(\partial U / \partial p<0)$ are (1) to reduce the amplitude in the upper layer and (2) 


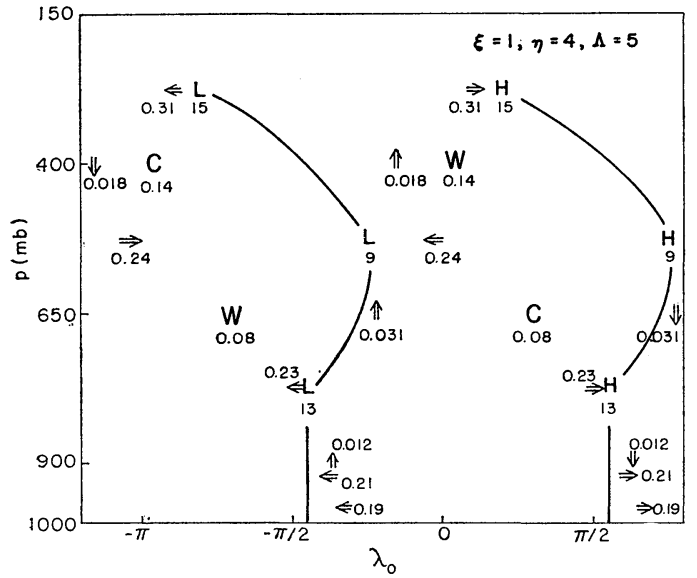

Fig. 4a. Vertical structure of Mode $(m=0, n=0)$ at $\varphi=15 \mathrm{~N}$ for $\alpha_{y}=(\mathrm{E} 1), \varphi_{0}=35, \zeta i=(\mathrm{H} 2)$, $D=10^{-5} \mathrm{sec}^{-1}, K_{1}=K_{2}=0, K_{3}=K_{4}=10 \mathrm{~m}^{2}$ $\sec ^{-1}, l=8, \eta=4, \xi=1$ and $A=5 \mathrm{~m} \mathrm{sec}^{-1}$. This case is referred to as Case (A).

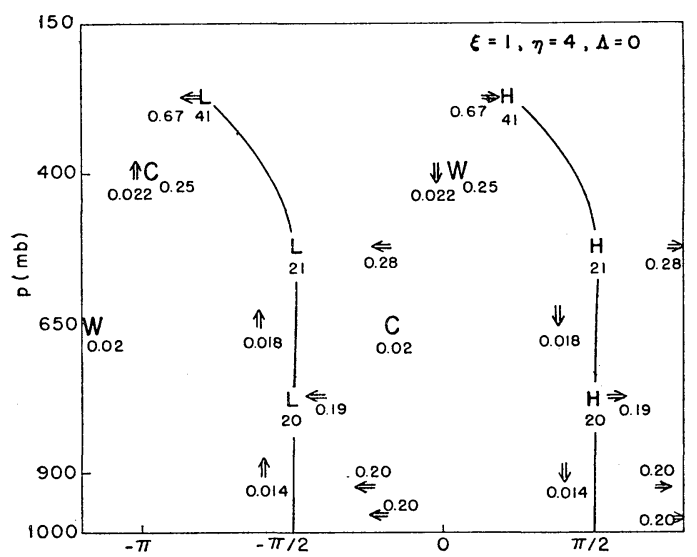

Fig. 4b. Same as Fig. 4a except for $\Lambda=0$.

to shift the location of the upward motion to the east of the pressure trough. The second effect is quite essential to the generation of the eddy available potential energy due to heat release. That is, in Fig. $4 \mathrm{~b}$ where $A=0$, heat release dissipates the available potential energy. This can be seen from the phase relation between $\omega_{3}(900 \mathrm{mb})$ and $\theta_{1}(400 \mathrm{mb})$ and that between $\omega_{3}$ and $\theta_{2}(650$ $\mathrm{mb})$. On the contrary, in Fig. $4 \mathrm{a}$ where $\Lambda=5 \mathrm{~m}$ $\mathrm{sec}^{-1}$, heat release creates the available potential energy. From the comparison of these figures we can see that the modification of $\omega_{3}$-field due to vertical shear is essential to producing the available potential energy in the upper layer. This is not true for a region near the equator. This point and the significance of the first effect of the

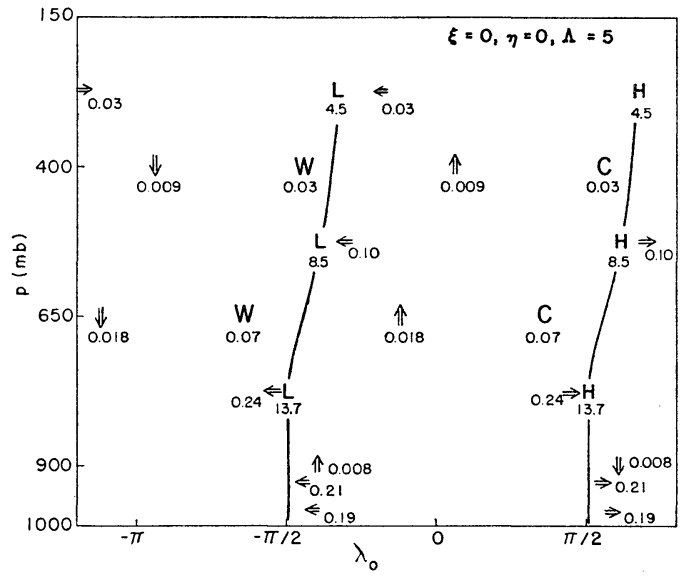

Fig. 4c. Same as Fig. 4a except for $\eta=0$ and $\xi=0$.

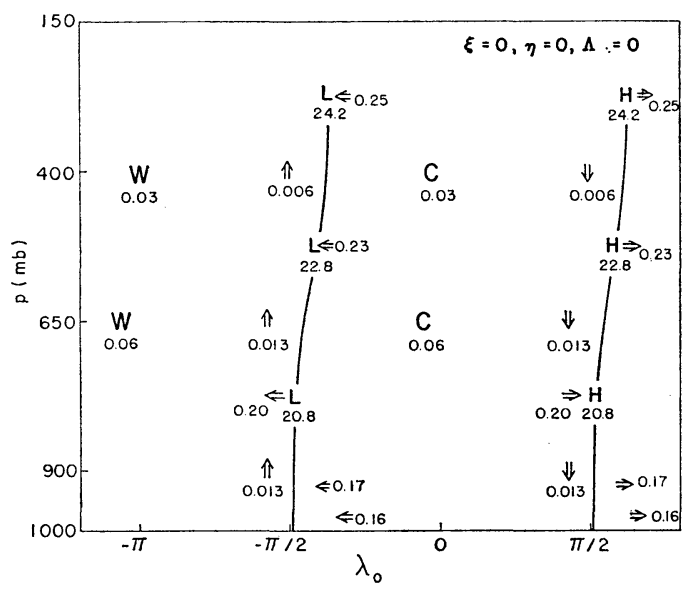

Fig. 4d. Same as Fig. 4a except for $\eta=0$, $\xi=0$ and $\Lambda=0$.

vertical shear will be mentioned later.

A notable effect of heat release on the vertical structure is found in the westward tilt of the trough axis in the upper layer. This is seen from the comparison of Fig. 4a with Fig. 4c and from that of Fig. 4b with Fig. 4d. It is also found that heat release in the upper layer significantly acts to increase the amplitude in the upper layer, particularly in the presence of the vertical shear.

The vertical structure shown in Fig. 4a is quite similar to Fig. 23 of paper $\mathrm{Y}$ except for the phase of $u$ in the lower layer. If we increase the vertical resolution of the finite difference, a vertical structure similar to that shown in Fig. 12 in paper $\mathrm{Y}$ may be expected (except for u-field). 


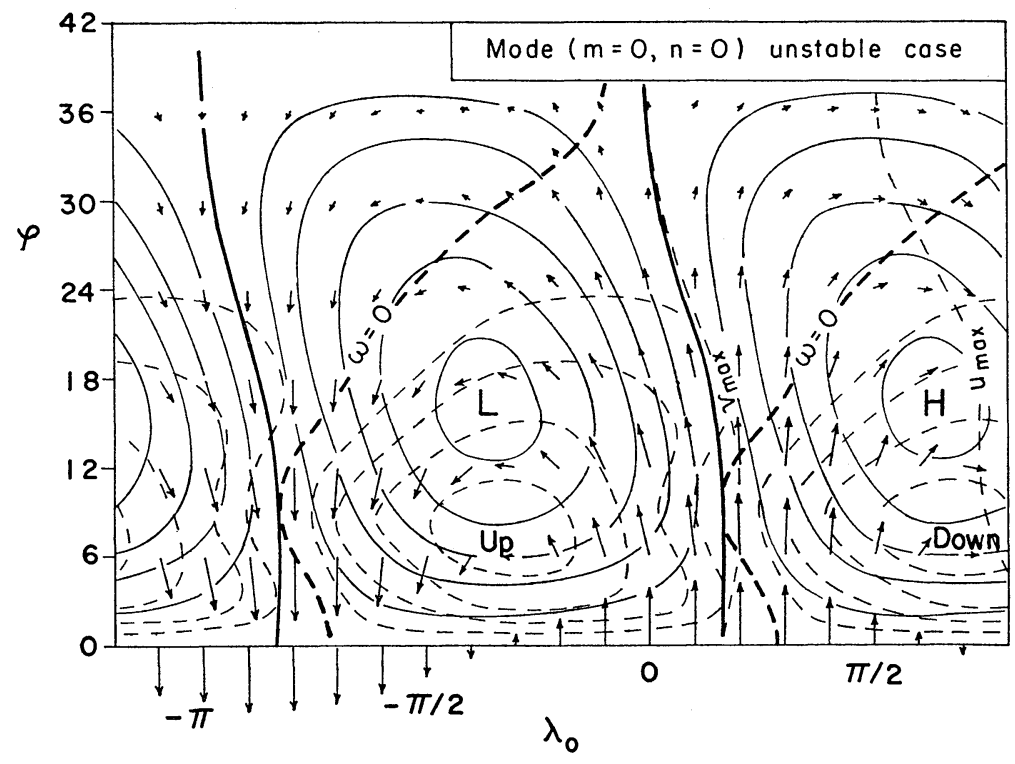

Fig. 5. Horizontal structure of Mode $(m=0, n=0)$ at $650 \mathrm{mb}$ in Case (A).

\subsection{Horizontal structure}

Figure 5 shows the horizontal structure at 650 $\mathrm{mb}$ in the same case as that shown in Fig. 4a. Hereafter, this case will be referred to as Case (A). The fields of $u, v$ and $\phi$ are made by averaging the values at $525 \mathrm{mb}$ and $775 \mathrm{mb}$. Since $v$ is symmetric and $u, \omega, \phi$ and $\theta$ are antisymmetric with respect to the equator in Mode $(m=0, n=0)$, only the Northern Hemisphere is illustrated. The field of $\phi$ is drawn by the solid lines, horizontal wind field by arrows and the vertical motion field by the dashed lines. It is found that the center of a low (indicated by $L$ ) is located around $16 \mathrm{~N}$, which is slightly south of the latitude $(20 \mathrm{~N})$ in the case of $h=\Lambda=D=K_{j}=0$. The wind field is quite ageostrophic in very low latitudes. This is a feature of this mode which is found for any values of parameters.

A notable feature is found in the vertical motion field. Stronger upward motions are located from the south to the east of a low pressure center and the latitude of a maximum upward motion is about $7 \mathrm{~N}$ at this level. In another paper (Yamasaki, 1971) it was shown that extrema of frictional convergence are located at latitudes where the absolute value of the Coriolis parameter is equal to the frequency of Rossby wave in the absence of a zonal current. For $l=8$, this latitude is about 6 degrees. When a zonal current is present, this critical latitude is approximately determined from a condition

$$
\nu+l \alpha_{\nu}= \pm f
$$

where $\alpha_{\nu}$ is an angular velocity of a zonal current near the surface at the critical latitude. When a zonal current has a vertical shear, vertical motion associated with the vertical shear is also caused. However, the latitude of the maximum vertical motion in the case under consideration is essentially determined from (4.1). We can easily understand that heat release around the critical latitude is of special importance in the stability of Mode $(m=0$, $n=0$ ). A large part of the eddy available potential energy is produced by heat release associated with this frictional convergence. The relation between the stability and the horizontal profile of heat release, which was discussed before (Table 1), is consistent with the above result.

Another feature of the vertical motion field is that its phase tilts eastward with decreasing latitude in very low latitudes, as pointed out by Yamasaki (1971). This property is much more notable at $900 \mathrm{mb}$ than at $650 \mathrm{mb}$. Because of this property, upward motion near the equator is located to the east of the trough even when vertical shear of a zonal current is absent. Therefore, it is possible in very low latitudes that the eddy available potential energy be produced by heat release without vertical shear. 


\subsection{Amplitude distribution}

Fig. 6 shows the amplitudes of $u, v$ and $\omega$ as functions of $\phi$ and $p$ for Case (A). It is seen that a maximum amplitude of $u$ is located at $16 \mathrm{~N}$, which is slightly south of the latitude $(21 \mathrm{~N})$ in the case of $A=h=0$. This equatorward shift is essentially due to an easterly current in low latitudes. The amplitude of $v$ has two positive extrema in Fig. 6. When a vertical shear of a zonal current is absent, the amplitude of $v$ takes a maximum at the equator. The secondary maximum located at $12 \mathrm{~N}$ is a result of existing vertical shear and heat release in the upper layer.

As mentioned before, the amplitudes of $u$ and $v$ in the upper layer is sensitive to the intensities of the vertical shear and heat release. The vertical shear $(\partial U / \partial p<0)$ acts to suppress the amplitudes, whereas heat release in the upper layer acts to increase it. This is one of significant features of mode $m=0$. For wind profile (E2) where vertical
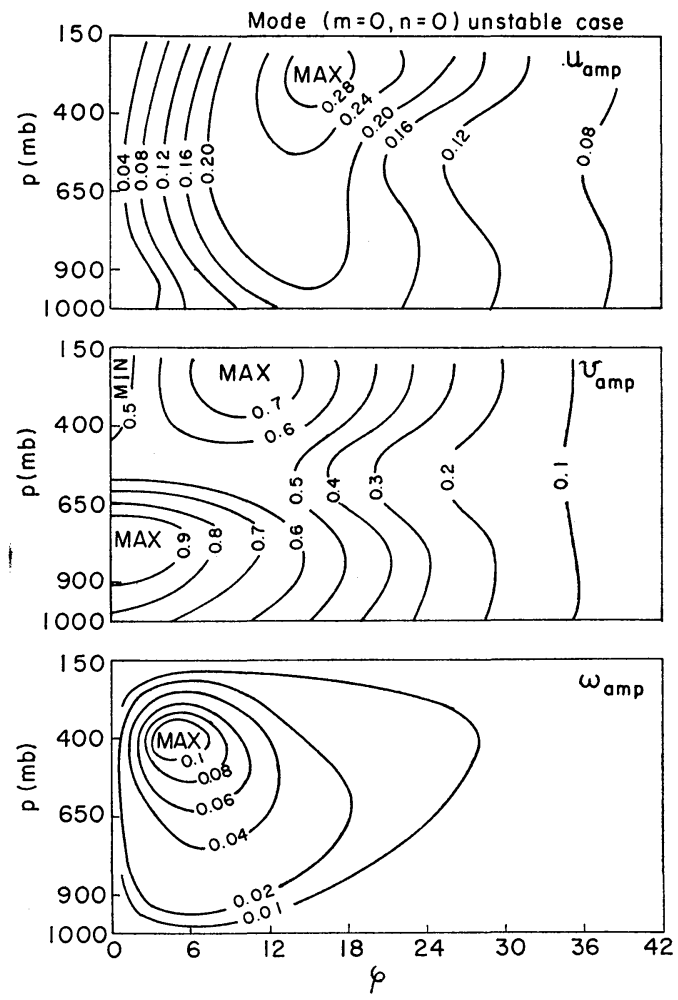

Fig. 6. Amplitudes of $u, v\left(\mathrm{~m} \mathrm{sec}^{-1}\right)$ and $\omega\left(10^{-3}\right.$ $\left.\mathrm{mb} \mathrm{sec}^{-1}\right)$ as functions of $\varphi$ and $p$ for Mode $(m=0, n=0)$ in Case (A). The maximum amplitude of $v$ is taken to be $1 \mathrm{~m} \mathrm{sec}^{-1}$. shear is weak near the equator, the amplitude of $v$ and $u$ in the upper layer become much larger in very low latitudes.

The lowest part of Fig. 6 shows that a maximum amplitude of $\omega$ is located at $400 \mathrm{mb}$ of $5 \mathrm{~N}$, which is slighty south of the latitude $(6 \mathrm{~N})$ of a maximum vertical motion at $900 \mathrm{mb}$. The maximum vertical $p$-velocity is about $0.1 \times 10^{-3} \mathrm{mb} \mathrm{sec}^{-1}$ for the maximum $v$-amplitude of $1 \mathrm{~m} \mathrm{sec}^{-1}$. The ratio of the amplitude at $400 \mathrm{mb}$ to that at 900 $\mathrm{mb}$ is about 3.2 at $9 \mathrm{~N}$ and 3.8 at $3 \mathrm{~N}$. These large values are closely related to the large value of $\eta$ adopted. In a case where a maximum value of $h$ is taken to be 2.5 in paper $\mathrm{Y}$, this ratio is about 2 (see Fig. 12 in paper Y). Since a large value of $h$ is required for the instability of mode $m=0$ in the present model where heat release is assumed to be released in the layer of the 500 mb depth, resulting vertical motion field appears to be also somewhat unrealistic.

The amplitude of $\theta$ (not shown) is a maximum around $11 \mathrm{~N}$ in the lower layer and around $14 \mathrm{~N}$ in the upper layer, while $\phi$-amplitude is a miximum around $16 \mathrm{~N}$ at all levels.

\section{6. energy budget}

Figure 7a shows the energy budget for Case (A). $A_{E 1}$ and $A_{E 2}$ indicate integrated values (with respect to $\varphi$ ) of eddy available potential energy corresponding to $\theta_{1}{ }^{2}$ and $\theta_{2}{ }^{2}$, respectively.

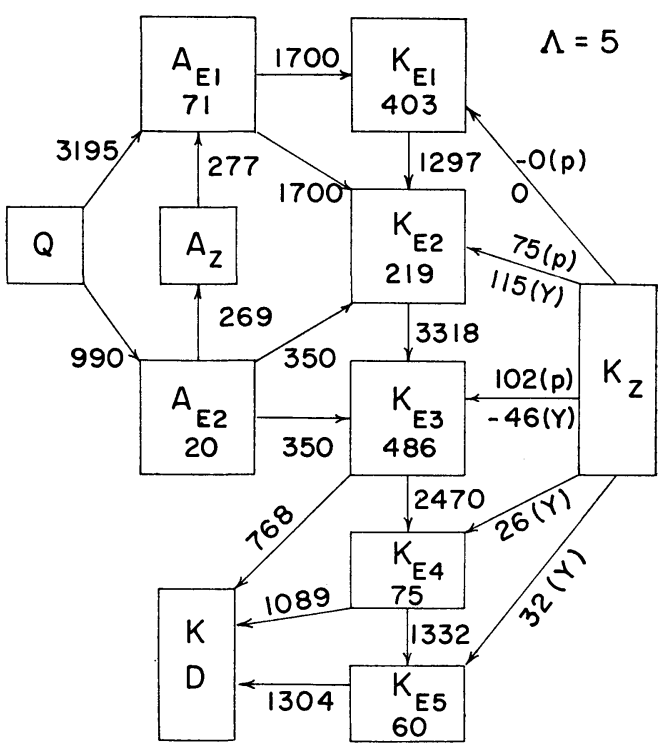

Fig. 7a. Energy budget for Mode $(m=0, n=0)$ in Case (A). For detail see text. 
$K_{E j}(j=1,2,3,4,5)$ indicate eddy kinetic energy in each layer. The numbers in these boxes show the time change of energies. The arrows directed from $Q$ to $A_{E}$ mean the production of eddy available potential energy due to heat release. The vertical flux of potential energy is indicated by the arrows between $K_{E j}$ and $K_{E j_{+} 1}(j=1,2,3$, $4)$. The arrows directed to $(K, D)$ indicate the dissipation of kinetic energy due to vertical eddy viscosity and surface friction. The arrows between $K_{Z}$ and $K_{E j}$ attached $(p)$ mean the conversion from zonal kinetic energy to eddy kinetic energy through the term $u_{\omega} \partial U / \partial p$. The arrows attached $(Y)$ indicate the conversion through the term $u v \partial U / \partial y$. It is found that most of $A_{E}$ is produced by heat release in the upper layer since $\eta$ is taken to be much larger than $\xi$. This is the main source of $K_{E}$. When we see the energy budget in the entire domain, $A_{E}$ produced by heat release is generally larger than the conversion of $A_{E}$ to $K_{E}$. In such a case the conversion between $A_{E}$ and zonal available potential energy $A_{z}$ is not important. In some cases, however, the conversion from $A_{z}$ to $A_{E}$ in the upper layer makes a significant contribution to the increase in $A_{E}$ in the entire domain. Fig. 7a also shows that a conversion from $K_{Z}$ to $K_{E}$ takes place through both terms $u v \partial U / \partial y$ and $u \omega \partial U / \partial p$. The amount is, however, small in the kinetic energy budget.

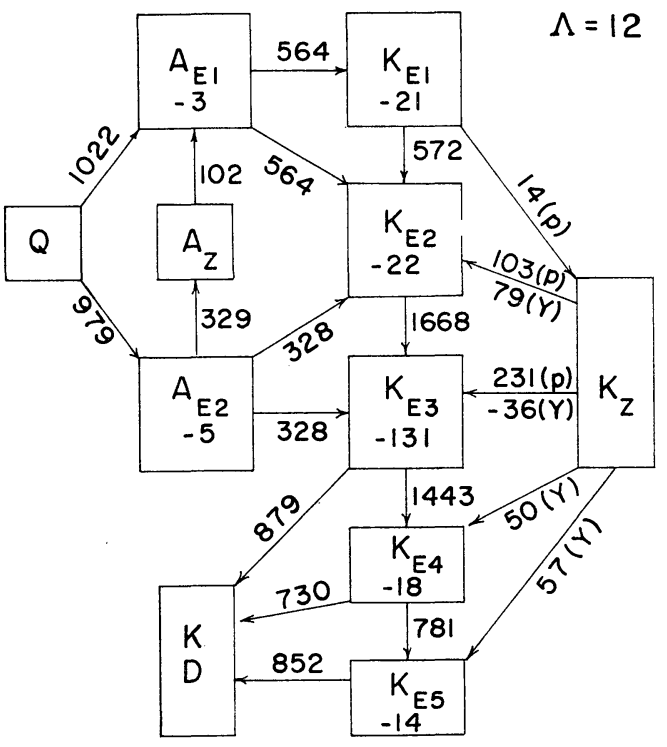

Fig. 7b. Same as Fig. 7a except for $\Lambda=12 \mathrm{~m}$ $\mathrm{sec}^{-1}$ (damped case).
When the vertical shear becomes too strong, Mode $(m=0, n=0)$ again becomes stable, as shown in Fig. 2. The wave of $l=8$ is damped for $\Lambda=12 \mathrm{~m} \mathrm{sec}^{-1}$. In order to understand this result the energy budget for this case is shown in Fig. 7b. A notable difference between the energy budgets for $\Lambda=5 \mathrm{~m} \mathrm{sec}^{-1}$ and $12 \mathrm{~m} \mathrm{sec}^{-1}$ is found in the generation of $A_{E}$ due to heat release in the upper layer. This generation is smaller by about one third than for $\Lambda=5 \mathrm{~m} \mathrm{sec}^{-1}$. As mentioned before, one of the effects of the vertical shear is to reduce the amplitude in the upper layer. Therefore, the reduction of the amplitude of the temperature in the upper layer makes the potential energy generation smaller. Thus the wave cannot maintain its kinetic energy against dissipation due to friction.

The result that the wave is unstable for intermediate intensities of the vertical shear in a region at some distance from the equator may be explained by the two different roles of the vertical shear such as the modification of $\omega_{3}$-field and that of $\theta$-field, as mentioned before. On the other hand, no or very weak vertical shear near the equator is a favorable condition. This may be attributed to the results that the modification of $\omega_{3}$-field by vertical shear is unnecessary for the generation of the eddy available potential energy and that the effect of the amplitude reduction of $\theta$ is predominant.

\section{Mode $(m=0, n=1)$}

Numerical solutions for Mode $(m=0, n=1)$ show that an extremum of the frictional convergence around the critical latitude where $f=\nu$ is not described for this mode. This is attributed to the large grid size used in this study. As discussed by Yamasaki (1971), Mode $(m=0, n=1)$ has another type of a maximum of frictional convergence, which is closely related to the vorticity field (Syono, 1949; Charney and Eliassen, 1949). In the absence of a zonal current a maximum of the relative vorticity is located at $15 \mathrm{~N}$ for $l=16,18 \mathrm{~N}$ for $l=10$ and $24 \mathrm{~N}$ for $l=6$. Frictional convergence associated with it takes a maximum at $11 \mathrm{~N}$ for $l=16,13 \mathrm{~N}$ for $l=10$ and $15 \mathrm{~N}$ for $l=6$ (Yamasaki, 1971). The frictional convergence field described by the present model appears to be similar to this type of convergence field. Even if the frictional convergence around the critical latitude is well described, its contribution to the instability property of this mode may 
be small compared with that of the convergence associated with the vorticity field. If this speculation is true, we can discuss the stability property of this mode without appropriate description of the frictional convergence around the critical latitude.

Fig. 8 shows the growth rate (unit: $10^{-7} \mathrm{sec}^{-1}$ ) as a function of $A$ and $l$. Other parameters are $\alpha_{y}=\mathrm{E} 1, \varphi_{0}=35, \eta=4.0, \xi=1.0, \zeta^{2}=\mathrm{H} 2, D=10^{-5}$ $\mathrm{sec}^{-1}, K_{1}=K_{2}=0$ and $K_{3}=K_{4}=10 \mathrm{~m}^{2} \mathrm{sec}^{-1}$. Compared with Fig. 2, it is seen that the preferred

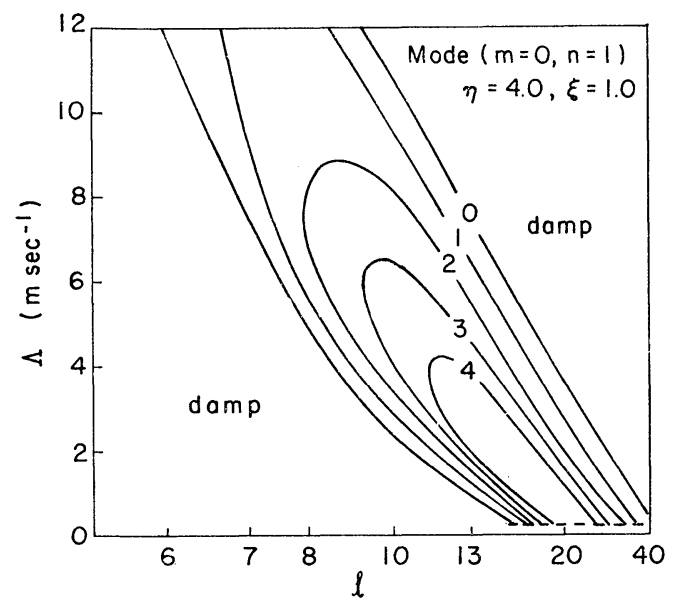

Fig. 8. Growth rates (unit: $10^{-7} \mathrm{sec}^{-1}$ ) of Mode ( $m=0, n=1)$ as a function of $\Lambda$ and $l$. The values of parameters are the same as those for Fig. 2. wavenumber of Mode $(m=0, n=1)$ is larger than that of Mode $(m=0, n=0)$. The preferred wavenumber is $11-10$ for $\Lambda=5 \mathrm{~m} \mathrm{sec}^{-1}$. The dependency of the instability on $A$ and $l$ is, however, qualitatively the same as that in the case of Mode ( $m=0, n=0)$.

The vertical structure of this mode at $15 \mathrm{~N}$ in the unstable case is similar to Fig. 4a except for $u$-field. Fig. 9 shows the horizontal structure at $650 \mathrm{mb}$ for $l=10$ and $A=5 \mathrm{~m} \mathrm{sec}^{-1}$. Only the Northern Hemisphere is illustrated because $v$ is antisymmetric and $u, \omega, \phi$ and $\theta$ are symmetric with respect to the equator. It is seen that the center of a low is located at $15 \mathrm{~N}$. On the other hand the amplitude of $\omega$ is a maximum around $10 \mathrm{~N}$, which is slightly south of the latitude (13N) in the case of $h=0$ and $A=0$. The most significant factor for this equatorward shift is probably the shift of the location of the maximum vorticity due to an easterly current. Stronger vertical motion is found from the southwest to the east of the low pressure center. The wind field is fairly geostrophic even near the equator in this mode.

Fig. 10 shows the amplitudes of $u$ and $v$ as functions of $\varphi$ and $p$. It is seen that $u$-amplitude takes a maximum at the equator, which is a characteristic property of this mode. A secondary maximum is found around $22 \mathrm{~N}$ (about $30 \mathrm{~N}$ for $l=10$ in the case of $\Lambda=0$ ). As in the case of Mode $(m=0, n=0)$, the amplitude in the upper

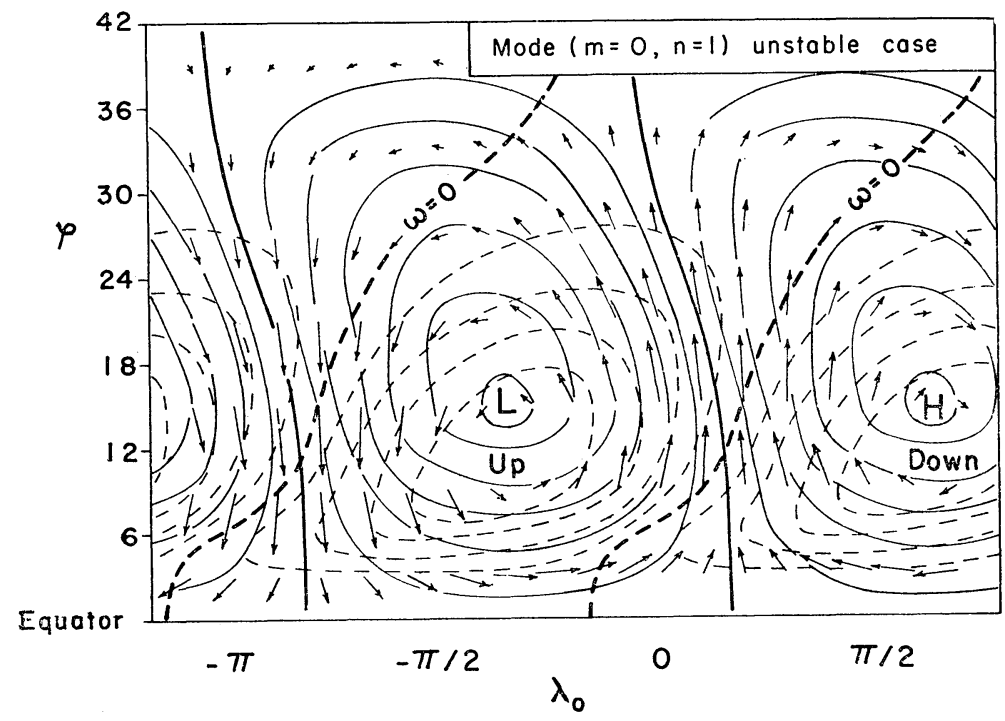

Fig. 9. Horizontal structure of Mode $(m=0, n=1)$ at $650 \mathrm{mb}$ in Case (A) for preferred wavenumber $l=10$. 

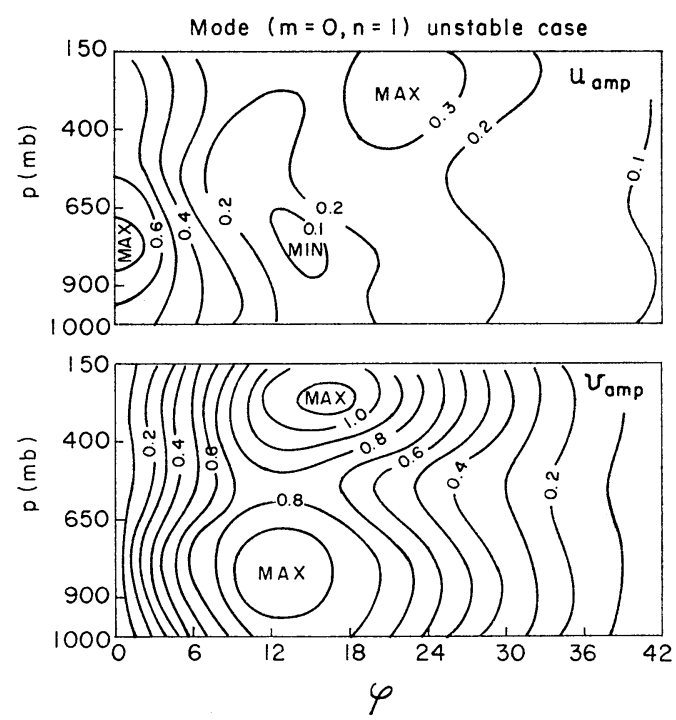

Fig. 10. Amplitudes of $u$ and $v$ as functions of $\varphi$ and $p$ for Mode $(m=0, n=1)$ in Case (A) for preferred wavenumber $l=10$. The amplitude of the maximum $v$ in the lower troposphere is taken to be $1 \mathrm{~m} \mathrm{sec}^{-1}$.

layer is strongly dependent upon the intensities of the vertical shear and heat release.

The solution for Profile (E2) shows that the maximum growth rate is almost the same as that for Profile (E1), although the preferred wavenumber is slightly larger. This implies that the stability property of Mode $(m=0, n=1)$ scarcely depends upon the vertical shear near the equator probably because frictional convergence at somewhat higher latitudes (around 10N) may. be particularly important in this mode.

\section{Some results for other types of unstable waves}

6.1. Mode $(m=1, n=0)$ and $(m=1, n=1)$

In contrast to mode $m=0$, the vertical motion is inherent to mode $m=1$. Therefore, it is possible that mode $m=1$ becomes unstable without surface friction and vertical shear of a zonal current. It appears that most of the essential properties of this type of unstable waves were described by Hayashi (1970)'s model in which neither surface friction nor wind shear of a zonal current were taken into account.

By using the present model with surface friction and wind shear, the following two points will be discussed in this study. One is the dependency of the preferred wavenumber on surface friction and vertical profiles of $h$ and the other is the effect of the vertical shear of the easterlies on the instability property. These investigations are made to confirm some results obtained in paper Y. Although the present model does not include the stratosphere and the artificial boundary condition $(2.17 \mathrm{~b})$ is used, essentially the same results would be obtained even for more realistic model as far as the following discussions are concerned.

The dashed line in Fig. 11a shows the growth

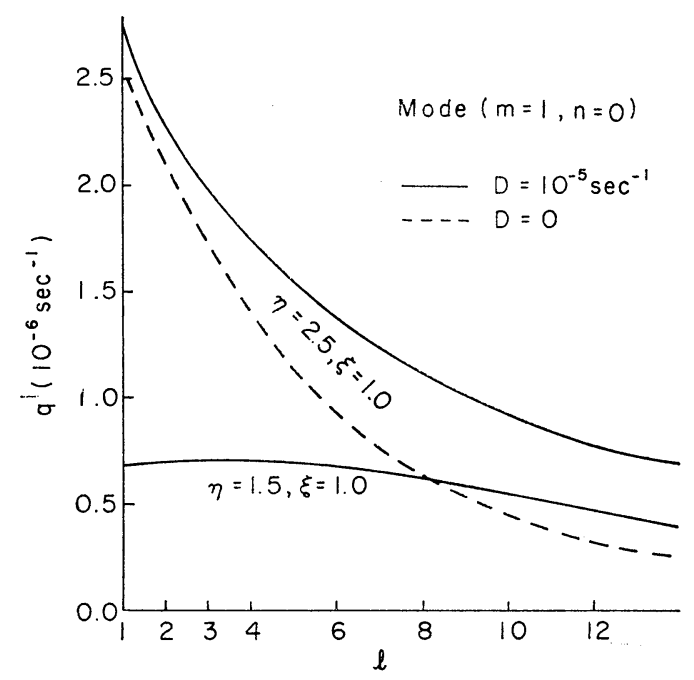

Fig. 11a. Growth rates of the mixed Rossbygravity Mode ( $m=1, n=0)$ as functions of $l$ for frictionless case (dashed line) and for $D=10^{-5} \mathrm{sec}^{-1}$ and $K_{3}=K_{4}=10$ $\mathrm{m}^{2} \mathrm{sec}^{-1}$ (solid lines). Other parameters are $\Lambda=0$ and $\zeta=(\mathrm{H} 1)$.

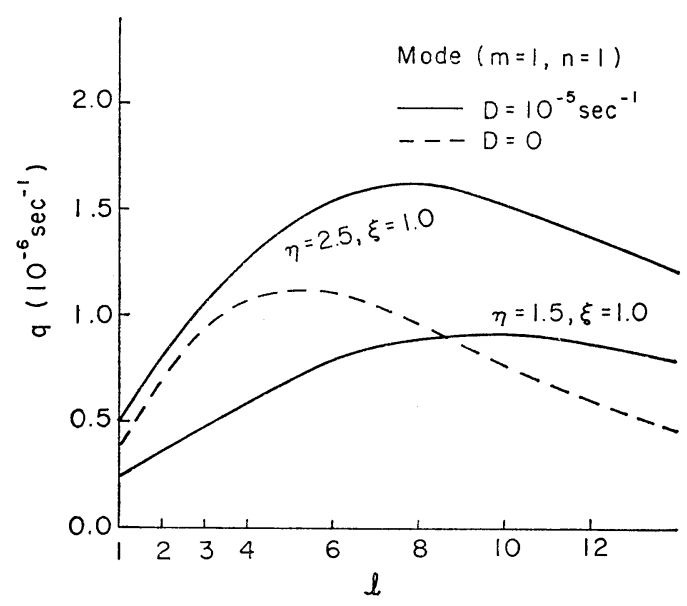

Fig 11b. Same as Fig. 11a except for Mode ( $m=1, n=1$ ). 
rate of Mode $(m=1, n=0)$ in the frictionless case as a function of $l$ for $\eta=2.5, \xi=1.0$ and $\Lambda=0$. As was shown by Hayashi (1970), the growth rate of this mode in frictionless case increases monotonously with decreasing wavenumber. This is not in agreement with the result for a two-dimensional model in paper $Y$. The wave is neutral for $\eta=1.5$ and $\xi=1.0$. When surface friction is incorporated, the wave becomes unstable even for smaller values of $\eta$. The solid lines indicate the growth rates for $D=10^{-5} \mathrm{sec}^{-1}$, $K_{1}=K_{2}=0$ and $K_{3}=K_{4}=10 \mathrm{~m}^{2} \mathrm{sec}^{-1}$ and for two combinations of $\xi$ and $\eta$. It is seen that the wave is unstable even for $\eta=1.5$ and that the waves with $l \leq 5$ have almost the same growth rates.

The growth rates for Mode $(m=1, n=1)$ are shown in Fig. 11b. As was shown by Hayashi (1970) the preferred wavenumber of this mode is about 6 in the absence of surface friction. This figure shows that the wavenumber becomes larger by the inclusion of surface friction. For $\eta=2.5$ and $\xi=1.0$, the preferred wavenumber is found to be about 8 , and for $\eta=1.5$ and $\xi=1.0$ it is about 10. It may be concluded that the preferred scale is decreased with decreasing amount of heat in the upper troposphere. This property is not noticeable in mode $m=0$.

Fig. 12 shows the growth rate of Mode $(m=1$, $n=1)$ as a function of $\Lambda$ and $l$. In this case we take $\eta=1.5, \xi=1.0$ and $D=10^{-5} \mathrm{sec}^{-1}$. It is found that both the preferred wavenumber and

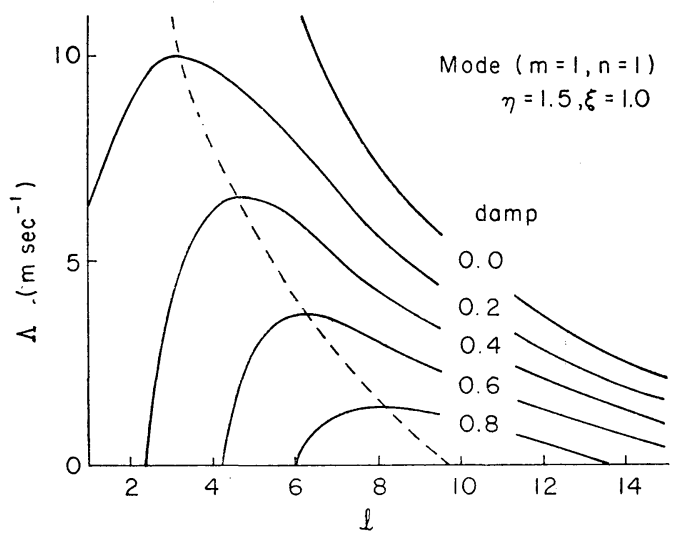

Fig. 12. Growth rates (unit: $10^{-6} \mathrm{sec}^{-1}$ ) of Mode $(m=1, n=1)$ as a function of $\Lambda$ and $l$ for $\alpha_{y}=(\mathrm{E} 1), \quad \varphi_{0}=30, \quad \eta=1.5, \quad \xi=1.0$, $\zeta=(\mathrm{H} 1), \quad D=10^{-5} \mathrm{sec}^{-1} \quad K_{1}=K_{2}=0 \quad$ and $K_{3}=K_{4}=10 \mathrm{~m}^{2} \mathrm{sec}^{-1}$. upper critical wavenumber decrease with increasing $\Lambda$.

\subsection{Mode (ES)}

As mentioned in Section 1, Mode (ES) refers. to a baroclinic unstable wave of the lowest vertical mode, greatly modified by heat release. Since the vertical resolution of the present model is too coarse to properly describe the growth rate and the vertical structure of this mode, we shall describe only a few results which can be probably concluded by the present model.

At first, we consider Profile (E3) where horizontal shear of a zonal flow is absent. We take $N=7, \quad \varphi_{B}=42, \quad \eta=4.0, \quad \xi=1.0, \quad \zeta^{i}=1(i=1,2,3$, 4), $\quad \zeta^{5}=2 / 3, \quad \zeta^{6}=1 / 3, \quad \zeta^{7}=0, \quad D=10^{-5} \mathrm{sec}^{-1}$, $K_{1}=K_{2}=0$ and $K_{3}=K_{4}=5 \mathrm{~m}^{2} \mathrm{sec}^{-1}$. For $\Lambda=10$ $\mathrm{m} \mathrm{sec}^{-1}$, we have some unstable waves. We shall limit our discussions to the lowest meridional mode which is most unstable among them. The latitudinal profile of the amplitude of $v$ for $l=13$ is shown by curve (E3) in Fig. 13. Since the

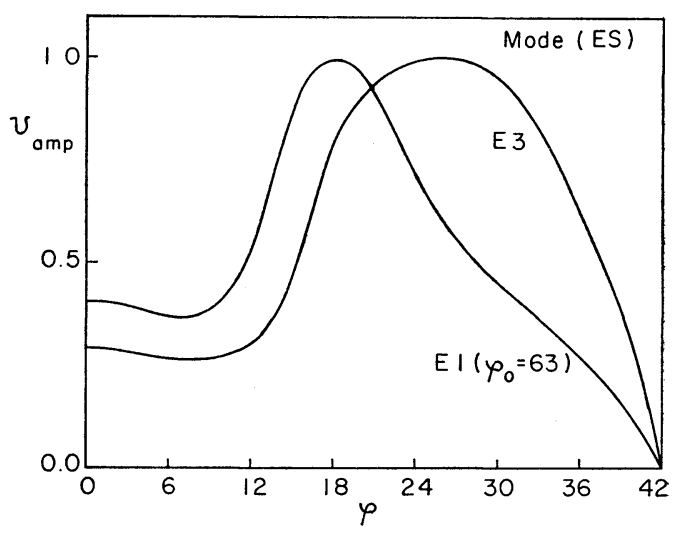

Fig. 13. Latitudinal profiles of the average amplitudes of $v_{1}, v_{2}$ and $v_{3}$ in Mode (ES) for two profiles of zonal flow.

profile is somewhat different at each level, an average of the profiles of $v_{1}, v_{2}$ and $v_{3}$ is shown in this figure. It is interesting to note that a maximum amplitude is located not at the equator but at relatively high latitudes. The amplitude of $u$ (not shown) has two extrema. These are located at both sides of the latitude where $v$ amplitude is a maximum. These results are consistent with the result obtained in a twodimensional model that Mode (ES) is more unstable for larger Coriolis parameter. The profiles of the amplitudes of $\omega, \theta$ and $\phi$ (not 
shown) have the same features as those of $v$ profile. It should be remarked that $\omega_{3}$-field is closely related to the vorticity field in this mode. The solution further shows that the trough axis has no appreciable tilt in the horizontal direction.

In the following we consider Profile (E1). The case of infinite value of $\varphi_{0}$ corresponds to Profile (E3). The growth rate of Mode (ES) decreases with decreasing $\varphi_{0}$. The mean latitudinal profile of the amplitude of $v$ for $\varphi_{0}=63$ is shown by curve (E1) in Fig. 13. The decrease in the amplitude at higher latitudes is notable and the position of the maximum amplitude shifts to lower latitudes. These results can be understood from the property of this mode in which vertical shear of a zonal flow, particularly at higher latitudes, is important. This mode becomes almost neutral for $\varphi_{0}=54$ (and for the values of parameters described before).

For Profile (E2) where the maximum vertical shear is located at $18 \mathrm{~N}$, Mode (ES) is much more unstable than for Profile (E1). When $\varphi_{0}$ is decreased from infinity to 54 , the growth rate is found to be not much decreased. Since the discussion for strong horizontal shear is probably unsatisfactory because of small $N$, we shall not discuss the case of smaller $\varphi_{0}$.

Numerical calculations by changing the values of $\xi, \eta, A$, and $l$ show that the dependency of the instability property of Mode (ES) on these parameters are similar to that obtained in paper Y. In addition the vertical structure is also similar provided that the horizontal shear of a zonal flow is weak.

One of remaining interesting problems may be the structure in the presence of strong horizontal shear. Although it is the best way to discuss this problem by the use of a primitive equation model with high resolution, the use of a quasigeostrophic model is an easy way for this purpose. It appears that such a model is fairly justified for the discussion of Mode (ES).

\subsection{Tropical cyclone mode}

When the value of $h$ in the lower layer is large, short waves $(l>40)$ become most unstable. The unstable wave of this kind corresponds to the tropical cyclone mode found by Ooyama (1964) and Charney and Eliassen (1964). The dependencies of the growth rate and the vertical structure on $\xi$ and $\eta$ were discussed by Syōno and Yamasaki. (1966). A cold core in the lower troposphere, which is often observed in the tropical cyclone at earlier stage (Yanai, 1961), can be easily described by the model. It is evident that smaller $\xi$ and larger $\eta$ are favorable conditions for a cold core (Fig. 2 of Yamasaki, 1968b). Several properties of this mode which have been inferred from the previous studies can be confirmed by the present model. For example, heat release particularly at higher latitudes of the tropics is one of favorable conditions for the growth of this mode. This is consistent with the result that its growth rate in a two-dimensional model increases with increasing Coriolis parameter. Numerical calculations further show that the latitude of a maximum intensity of upward motions nearly coincides with that of maximum value of $h$, whereas the center of a low pressure is located at a latitude higher than this. In other words, a maximum upward motion tends to appear to the south of the center of a low pressure. Since the frequency of this mode is very small (about $1.5 \times 10^{-6} \mathrm{sec}^{-1}$ for $l=80$ and $3 \times 10^{-6} \mathrm{sec}^{-1}$ for $l=40$ ), it is not likely that frictional convergence is important at the critical latitude where $f=\nu$. In the numerical calculations with $\Delta \varphi=3$ the phase of vertical motion field was almost the same as that of pressure field even near the equator. A notable feature obtained in the present model is that the trough axis tilts eastward with increasing latitude in lower latitudes of the tropics. It was found that the larger the longitudinal scale the larger the eastward tilt because of increasing $\beta$-effect.

The effect of the vertical shear of a zonal flow on the tropical cyclone mode was studied by Ooyama (1971) and in paper Y. Essentially similar results have been obtained in the present model.

\subsection{Kelvin wave}

It was shown by Hayashi (1970) that Kelvin wave becomes unstable under the assumption (2.6). This problem will not be studied in this paper.

\subsection{Gravity wave}

As was mentioned in paper $\mathrm{Y}$ and shown by Hayashi (1970), gravity waves also become unstable with large amplification rates when the value of $\eta$ is large. This kind of unstable gravity waves are essentially the same as those which were discussed by Syōno and Yamasaki (1966) and which appeared in the numerical experiments on tropical cyclone development by Yamasaki $(1968 \mathrm{a}, \mathrm{b}, \mathrm{c})$. Since the frequencies of these waves 
are very high, it is reasonable to consider that the values of $h$ are much smaller for gravity waves than for Rossby waves. Under such an assumption Hayashi (1971) showed that it is possible to avoid the amplification of gravity waves and to obtain Rossby waves or Kelvin waves as a preferred mode. However, when we attempt to discuss wave properties by the timeintegration of primitive equations, the rapid amplification of gravity waves will not be avoided except for certain profiles of $h$. It is strongly desired to find a heating parameterization which does not excite gravity waves.

\section{Discussion with observations}

In this section we shall discuss in comparison with observed waves, particularly with the easterly wave. It was suggested in paper $Y$ that there exist three kinds of easterly waves such as Mode (ES), (E) and (HB). These waves are further classified by different meridional modes. As discussed in this study, Mode $(m=0, n=0)$ and $(m=0, n=1)$ are Mode (E) type wave with which we are most concerned among $m=0$ mode of various meridional modes. As for Mode (HB) type wave, Hayashi (1970) showed that the preferred scale of the mixed Rossby-gravity wave is planetary scale under the assumption (2.6). Since this scale is scarcely changed by the presence of friction and zonal flow, this mode may be excluded from the present discussion as to the easterly wave. Hayashi also showed that the baroclinic Rossby mode of $n=1$ takes a maximum growth rate at $6,000-7,000 \mathrm{~km}$. The wave referred to as Mode $(m=1, n=1)$ in this paper corresponds to this Rossby wave. As shown in Section 6.1, this preferred scale becomes smaller $(4,000 \mathrm{~km})$ in the presence of surface friction if heat release in the upper troposphere is not very strong. Therefore, this mode can be regarded as Mode (HB) type wave which may be interesting from the standpoint of the study of the easterly wave. Table 2 summarizes the properties of three kinds of waves (four waves) which possibly correspond to the easterly wave. Many of features of Mode $(m=1, n=1)$ are referred from Hayashi (1970). As for Mode (ES), the lowest meridional mode is chosen since this mode is most unstable. In addition to these waves listed in this table, higher meridional modes such as Mode $(m=0$, $n=2)$ and ( $m=1, n=2)$ may also be a kind of the easterly wave, but this problem is not discussed in this study.

The easterly wave model described by Riehl (1954) has the following features: (1) The wavelength is about $1,500-2,000 \mathrm{~km}$. (2) Cumulus clouds and frequent showers or rain are usually observed to the rear (east) of the trough line, indicating that ascending motions are also located to the east of the wave axis. (3) The lowest temperatures are also located slightly to the east of the trough; the easterly wave is cold cored. (4) As a result of the feature (3), the trough line is tilted eastward with increasing height. (5) Although a strong wave penetrates to the tropopause, the wave amplitude in weak and moderate easterly waves is most prominent in the lower and middle troposphere. (6) The wave amplitudes of pressure and meridional wind are maxima at some distance away from the equator. (7) The easterly wave moves westward at a speed of low level easterlies. (8) The period of the passage of the wave is 3-4 days. Although these features were based upon several case studies, most of them have been supported by further case studies (Yanai, 1961, 1963, 1968; Yanai and Nitta, 1967; Krishnamurti and Baumhefner, 1966) and by some spectrum analysis (Nitta, 1970a and others). In view of the features (6) and (7), it was suggested in paper $Y$ that Mode (ES) is most similar to the easterly wave of the type described by Riehl (1954), although the temperature field (3) was not well simulated.

The easterly wave model presented by Palmer (1952) is in part different from that of Riehl (1954) in the sense that the wave amplitude of $v$ is a maximum at the equator and that convergence field is nearly antisymmetric with respect to the equator. The spectrum analysis by Rosenthal (1960) for the data during the period from April to July in 1956 showed that $v$-spectra at 5,000 ft. level reached distinct maxima at 3-5 day period only at the stations lower than $10 \mathrm{~N}$. $\mathrm{He}$ concluded that they were reflections of the passage of equatorial easterly waves of the type described by Palmer (1952). The recent spectrum analysis by Wallace and Chang (1969) showed that the spectra of $v$ associated with the period of 4-5 days was a maximum near the equator for the period 1963. Furthermore, they suggested that the wave propagated westward faster than the easterly current. The wavelength was estimated to be $3,000 \mathrm{~km}$. These results strongly suggest that the easterly wave of Mode $(m=0, n=0)$ type should exist in the tropics. 
Table 2. Three types of unstable waves whose horizontal wavelengths are several thousand kilometers.

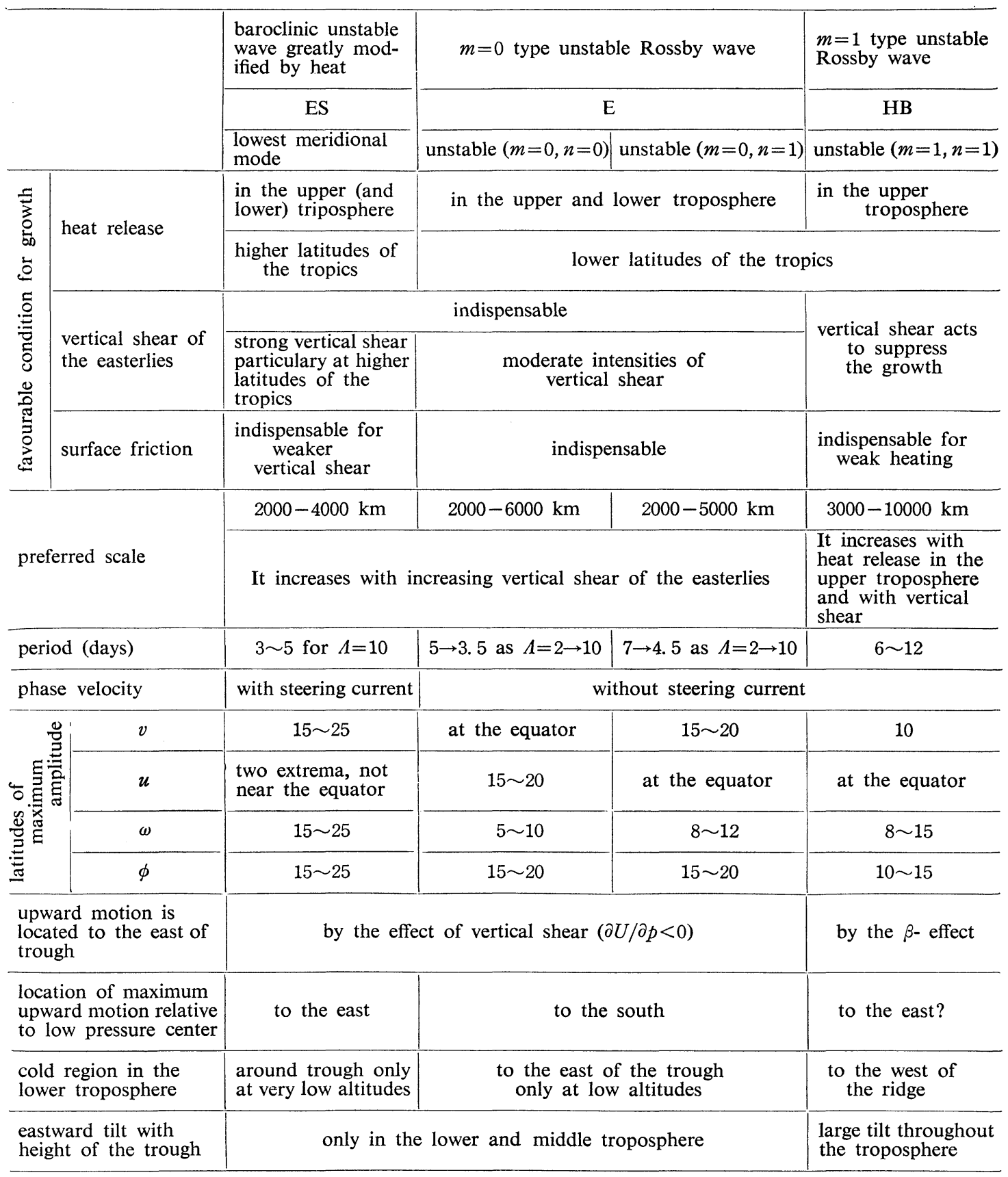

As an extension of Wallace and Chang (1969), more detailed spectrum analysis was performed by Chang et al. (1970) using the data for 1964. Their study appears to be most attractive to the present author who wishes to compare the properties of Mode $(m=0, n=0)$ with observed waves. The results of their spectrum analysis for the western Pacific station data have many common features to Mode $(m=0, n=0)$ as follows: (1) The phases of $v$ were nearly in phase at all levels throughout the troposphere at some stations, while at some other stations the phase 
of $v$ above $200 \mathrm{mb}$ level leaded $0.3-0.45$ cycle the phase of $v$ in the middle and lower troposphere. Both small and large phase differences can be simulated by Mode (E) (see Fig. 4a in this paper and Fig. 25b in paper Y). (2) The meridional wind component $v$ leaded temperature by 0.25 0.45 cycle below $800 \mathrm{mb}$. This means that the lowest temperature is situated $0-0.2$ cycle to the east of the trough. Although the present fivelayer model could not simulate this feature, Mode (E) described by a multiple-layer model in paper $\mathrm{Y}$ is quite similar to this. In the layer between $200-500 \mathrm{mb}$, warmest region was located above the trough of the lower troposphere. The temperature at $125 \mathrm{mb}$ leaded that at $200-450 \mathrm{mb}$ by $0.4-0.45$ cycle. These are similar to Fig. 12 in paper Y. (3) The humidity (consequently upward motion) and temperature were nearly in phase in the upper troposphere. At the lower troposphere, maximum humidtity (and upward motion) were located $0-0.25$ cycle to the east of the trough. Except for the region near the equator, these are also quite similar to the property of Mode $m=0$. (4) The horizontal wavelength was $4,000 \mathrm{~km}$ in the troposphere. This scale was not found at $80 \mathrm{mb}$. This means that the wave was almost confined to the troposphere. This is a typical property of Mode $m=0$ when a zonal current is not strong in the stratosphere. (5) The period of $v$-oscillation in the lower troposphere at Marshal Islands was 4-5 days. Taking account of the fact that the easterly current had a velocity of about $5 \mathrm{~m} \mathrm{sec}^{-1}$, the period of Mode $(m=0$, $n=0$ ) coincides with this. (6) The magnitude of $v$-amplitude was larger at lower latitude stations. In many respects the 4-5 day period oscillation in the troposphere analyzed by Chang et al. (1970) can be regarded as none of Mode $(m=1$, $n=0), \quad(m=1, n=1)$ and $(m=0, n=1)$. It is highly probable that the wave corresponds to Mode $(m=0, n=0)$. Unfortunately the latitudes of maximum amplitudes of $\omega, u$ and $\phi$ in Mode $(m=0, n=0)$ cannot be compared with observations because they did not make analyses concerning this point.

It should be mentioned here that there is a significant discrepancy between the feature of the wave analyzed by Chang et al. (1970) and that of Mode $(m=0, n=0)$. They showed that $u$ and $v$ were nearly in phase in the Northern Hemisphere. This feature is not simulated by any wave obtained in the present model.
Yanai et al. (1968) showed, by spectrum analysis for the western Pacific in 1962, that the wavelength associated with a spectral peak of winds with 4-5 day period in the lower troposphere was $5,000-6,000 \mathrm{~km}$. This estimated value is much larger than those by Riehl (1954), Wallace and Chang (1969), Chang et al. (1970) and others. The interpretation of this wave is not clear yet.

The eastward tilt of the trough axis with latitude has been often observed in the easterly wave. The trough axis in Mode $m=0$ tilts very slightly westward with latitude in the lower troposphere (Fig. 5) and eastward in the upper troposphere (not shown). On the other hand Mode (ES) has no appreciable phase tilt with latitude. Since these are the results obtained for weak horizontal shear of the easterlies, further studies are required. It may be interesting to mention that the tropical cyclone mode (TC) is similar to the observed easterly wave with respect to this feature when we consider the wavelength of $1,000-2,000 \mathrm{~km}$. Although the preferred scale of this mode is several hundred kilometers, the growth rate of this mode with a wavelength of $2,000 \mathrm{~km}$ is not so small. Furthermore, the cold cored structure in the lower troposphere is well simulated by this mode when heat release is sufficiently strong in the upper troposphere. A major difference between Mode (TC) and the easterly wave is found in the phase relation between $\omega$-field and $\phi$-field. In some cases it may be difficult to determine whether an observed wave should be identified with tropical cyclone mode or the easterly wave mode. Therefore, some of the features which are considered to be those of the easterly wave may be the features of the tropical cyclone mode.

In addition to the easterly wave Riehl (1948) noted the existence of another kind of large-scale disturbances at upper tropospheric level. Its horizontal scale was larger than that of lower tropospheric easterly waves and its period was about one week. Rosenthal (1960)'s spectrum analysis for $v$-field at $40,000 \mathrm{ft}$ level also supports this period (5-10 days), although the spectrum peak was not very distinct. There was no evidence that this spectrum peak decayed with latitude in the tropics. As in the case of lower tropospheric easterly waves, $v$-spectra tended to be greater than $u$-spectra for this period range. Yanai (1963) also noted this kind of large-scale disturbances. Yanai and Murakami (1970a) showed that a 
spectra peak at 7 day period was found for $u$ more notably than for $v$ in their analysis for the data of 1962. A further study (Yanai and Murakami, 1970b) showed that this oscillation was associated with symmetric $u$-field and antisymmetric $v$-field with respect to the equator. They suggested that this might correspond to $n=1$ mode of the baroclinic Rossby waves. According to Hayashi (1970), the period of the preferred wave of $n=1$ is 11 days, which is slightly larger than the period of the observed wave. Since the frequency of the baroclinic Rossby wave is dependent upon the stability and the intensity of easterlies, this discrepancy is not serious. The estimated wavelength by Yanai and Murakami (1970b) was $7,000 \mathrm{~km}$. Its amplitude was found to be largest around $8-12 \mathrm{~km}$. From these features it is most probable that this wave corresponds to $(m=1, n=1)$.

Wallace and Chang (1969) also noted a pronounced peak, particularly in $u$--spectra, at 10-15 day period in their analysis for the lower troposphere. Yanai and Murakami (1970a) showed that this peak was a maximum at $12 \mathrm{~km}$ level. If the horizontal wavelength is assumed to be more than $3,000 \mathrm{~km}$, there is little possibility that Mode $(m=0, n=0),(m=0, n=1)$ or $(m=1$, $n=0$ ) corresponds to this oscillation. If it is ture that $v$-amplitude is decreased with decreasing latitude, as analyzed by Wallace and Chang, this wave may be also Mode $(m=1, n=1)$.

In contrast to the four waves listed in Table 2 , the mixed Rossby-gravity mode as well as Kelvin mode are waves whose existence has been demonstrated by many observational studies. It has been established that the planetary-scale lower stratospheric wave discovered by Yanai and Maruyama (1966) is a kind of mixed Rossbygravity wave (Maruyama, 1967, 1968a, b; Lindzen and Matsuno, 1968 and others). Its existence in the upper troposphere was shown by Yanai et al. (1968). Hayashi (1970) showed that the unstable mixed Rossby-gravity mode under the assumption (2.6) is much more similar to Yanai-Maruyama wave than the neutral mode is. It is also very interesting to mention that the preferred scale of this mode in his model is not less than several thousand kilometers. This preferred scale is compared with the scale $(10,000 \mathrm{~km})$ of YanaiMaruyama wave.

For the justification of his model with the assumption (2.6) we need, at least, an observa- tional evidence that the wave is observed also in the lower troposphere. It appears that this evidence has been obtained by Nitta (1970a) and Chang et al. (1970) in their spectrum analysis for the eastern Pacific station data.

There remains a question as to whether the mixed Rossby-gravity mode $(m=1, n=0)$ accounts for the easterly wave with the horizontal scale of several thousand kilometers. Under an assumption other than (2.6), what would the preferred scale and other properties of this mode be? This may be one of interesting problems in the future.

\section{Summary and remarks}

As a continuation of the previous study (Yamasaki, 1969) the properties of wave disturbances found in a conditionally unstable model tropics were studied by the use of primitive equations on the spherical coordinates. The primary objective of this study was to investigate the properties of the wave that was referred to as Mode (E) in the previous paper. In the absence of friction, wind shear of a zonal current and heat release, this mode is reduced to the barotropic Rossby mode which is not associated with vertical motions. This kind of Rossby mode on the spherical coordinates was first studied by Haurwitz (1940b). To the author's knowledge the importance of this mode, however, has not been recognized from the standpoint of tropical meteorology.

The present study showed that when surface friction and heat release (2.6) were incorporated, the lowest $(n=0)$ and the second $(n=1)$ meridional modes of this type of Rossby waves became unstable for some combinations of the wavenumber and the vertical shear of the low latitude easterlies. The condition for instability and the vertical structure were quite similar to those obtained in the two-dimensional model of Yamasaki (1969). The three-dimensional structures of these modes were illustrated in Figs. 5 and 6 for $n=0$ and in Figs. 9 and 10 for $n=1$. The dependency of their structure on heat release and vertical shear of the easterlies was also discussed. Among various kinds of unstable waves discussed in this study, $n=0$ mode appeared to be most similar to the equatorial easterly wave of the type described by Palmer (1952) and that recently analyzed by Wallace and Chang (1969) and by Chang et al. (1970). On the other hand, we do 
not have observational evidence as to $n=1$ mode, but we may expect that more detailed and careful observational studies in future will reveal its existence.

Since the theoretical studies by Matsuno (1966), Rosenthal (1965) and Lindzen (1967) most of the subsequent studies have paid their attention to the baroclinic Rossby mode (including the mixed Rossby-gravity mode). Some properties of mode $m=1$ were also studied in this paper as an extention of Hayashi (1970). We confirmed some results, which were suggested by Yamasaki (1969), as to the effects of surface friction and the vertical shear of the easterlies. A further detailed discussion is being made by Hayashi.

In addition to the two kinds of Rossby waves mentioned above, the wave referred to as Mode (ES) appeared to be of special interest. This mode may be considered to be most similar to the easterly wave of the type described by Riehl (1954) and others. Unfortunately, the properties of this mode could not be fully discussed by the present model in which the resolution of the finite difference was coarse.

One of notable results of this study was found in a role of frictional convergence in very low latitudes. As discussed in another paper (Yamasaki, 1971), an extremum of frictional convergence is located at a critical latitude where the absolute value of the Coriolis parameter is equal to the frequency of the wave (with modification in the presence of zonal current). This has been also noted by Holton et al. (1971). In the case of the lowest meridional mode $(n=0)$, this type of convergence appeared to be important. In particular, the properties of Mode $(m=0$, $n=0$ ) was strongly controlled by heat release associated with the frictional convergence in the vicinity of this latitude (around $6 \mathrm{~N}$ for the most preferred wave). Although numerical solutions showed that this type of convergence was noticeable also in the mixed Rossby-gravity wave, the effect seemed to be not so essential as in the case of Mode $(m=0, n=0)$. For the waves with the meridional modes of $n=1$, it was most probable that the frictional convergence closely related to the vorticity field was more important than that related to this latitude. The maximum frictional convergence was located at latitudes lower than that of the maximum vorticity (Yamasaki, 1971). As for Mode (ES) and the tropical cyclone mode, frictional convergence was closely related to the vorticity field, and the phases of these fields were almost in phase even near the equator.

In this study the significance of the vertical shear of the basic zonal current has been discussed in some detail. On the other hand, the role of the horizontal shear has not necessarily been made clear. Since the vertical shear is indispensable to the instability of Mode $m=0$ and (ES), it is not easy to clarify the effect of horizontal shear itself on these modes. The important effect of horizontal shear may be recognized only by the fact that the intensity of vertical shear becomes a function of latitude. As for Mode $m=1$, it is possible to study the case where only the horizontal shear is present. As is easily expected, Mode $m=1$ becomes to propagate at a speed slower than a maximum easterly current for smaller wavelengths. Another effect of horizontal shear on Mode $m=1$ is to reduce its growth rate. Since the vertical shear also reduce the growth rate, the growth rate of Mode $m=1$ is not necessarily reduced by the presence of horizontal shear when the existence of horizontal shear makes mean intensity of vertical shear smaller.

It is undoubtedly one of the most important problems in the future to clarify whether the heat assumption (2.6) is valid for long waves and planetary-scale waves. The most significant criticism for the present study will be probably directed to this assumption. In this connection it may be important to mention the following points. In the present model the tropical cyclone mode and mode $m=1$ are much more preferred than Mode $m=0$ and Mode (ES). When heat release is strong in the lower troposphere (particularly 800 900 mb), the tropical cyclone mode is the most preferred mode. When heat release is strong not in the lower troposhere but in the upper troposphere, mode $m=1$ is most preferred. On the other hand, mode $m=0$ and (ES) are not obtained as the preferred mode for almost all profiles of $h$ (if $h$ is independent of the horizontal scale of the wave). For reasonable values of $h$ the growth rates of these two modes are less than $10^{-6} \mathrm{sec}^{-1}$ in the present model. Even if we admit that the growth rate is probably underestimated because of the coarse vertical resolution, the growth rate appears to be still too small. Although we have discussed these modes in comparison with the observed easterly waves, it is strongly desired to clarify whether or not 
these modes actually exist in the tropics. In order to improve the present model, detailed properties of observed waves are needed to be clarified.

In addition to the assumption (2.6), the model has many aspects which may not necessarily describe the actual atmosphere. For example, it is assumed in this study that $h$ is constant with respect to the longitude, but it is much more realistic to assume that $h$ is dependent upon the sign of the vertical motion at $900 \mathrm{mb}$. Furthermore, it may be expected that $h$ is more or less dependent upon the wind direction; that is, air at $10 \sim 15 \mathrm{~N}$ probably contains more water vapor in a region of the southerly wind than in a region of the northerly wind. As for the latitudinal profile of $h$ used in this study, it is only an assumption which has not been justified observationally. The profiles of zonal flows used are very simplified and idealized. The case of asymmetric heat release and zonal flow with respect to the equator was not discussed. There remain many questions to be studied in the future. Nevertheless, it may be considered that the present study has offered many information about the properties of waves in the conditionally unstable tropics.

Some of observed waves in the tropics may be waves in which condensation heat is not essential. For example, when the horizontal shear of the easterlies satisfies the condition for the barotropic instability (Kuo, 1949), Rossby waves may disappear and barotropic unstable waves are expected to occur. A study for this problem was made by Nitta and Yanai (1969) and it has been extended by Yamasaki and Wada (1971). These studies as well as a study by Lipps (1970) have been confined to the discussion of a twodimensional model in the horizontal plane. It is very attractive to clarify whether or not the barotropic unstable wave is similar to the easterly wave with respect to the vertical structure.

The pure baroclinic instability has been considered as unimportant in the easterly wave (Charney, 1963 and others). Recently Ooyama (1971) has shown that the second derivative of a zonal wind velocity with respect to height is important in the baroclinic instability and that the baroclinic unstable wave is of cold cored type in the lower troposphere when an easterly current has no or weak vertical shear in the lower troposphere.
Anothe possibility of the origin of waves in the tropics may be seeked for the energy propagation from the middle latitudes, as was discussed theoretically by Mak (1969) and Charney (1963, 1969) and demonstrated observationally by Nitta (1970b). For better understanding of tropical disturbances many theoretical and observational studies from various aspects are strongly desired. Finally it is added that the properties of a "forced" Rossby wave in the presence of heat release have been studied by Holton (1971).

\section{Acknowledgments}

The author expresses his hearty thanks to Prof. K. Ooyama who made it possible for the author to perform this study at New York University. This study would not have been possible in Japan. The author is also indebted to him for valuable comments and discussions. The author also wishes to thank Prof. T. Matsuno for valuable discussions at the early phase of this work and Prof. M. Yanai for valuable comments on the original manuscript.

\section{References}

Chang, C.P., 1970: Westward propagating cloud patterns in the tropical Pacific as seen from timecomposite satellite photographs. J. Atmos. Sci., 27, 133-138.

, V.F. Morris, and J.M. Wallace, 1970: A statistical study of easterly waves in the Western Pacific: July-December 1964. J. Atmos. Sci., 27, 195-201.

Charney, J.G., 1947: The dynamics of long waves in a baroclinic westerly current. J. Meteor., 4, 135162.

, 1963: A note on large-scale motions in the tropics. J. Atmos. Sci., 20, 607-609.

- 1969: A further note on large-scale motions in the tropics. J. Atmos. Sci., 26, 182185.

185. and A. Eliassen, 1949: A numerical method for predicting the perturbations of middle latitude westerlies. Tellus, 1, 38-54.

- 1964: On the growth of the hurricane depression. J. Atmos. Sci., 21, 68-75.

Haurwitz, B., 1940a: The motion of atmospheric disturbances. J. Marine Res., 3, 35-50.

1940b: The motion of atmospheric disturbances on the spherical earth. J. Marine Res., 3, 254-267.

Hayashi, Y., 1970: A theory of large-scale equatorial waves generated by condensation heat and accelerating the zonal wind. J. Meteor. Soc., Japan, 
48, 140-160.

1971: Instability of large-scale equatorial waves with a frequency-dependent CISK parameter. (To be published).

Holton, J.R., 1971: A diagnostic model for equatorial wave disturbances: the role of vertical shear of the mean zonal wind. J. Atmos. Sci., 28, 55-64.

, J.M. Wallace and J.A. Young, 1971: On boundary laver dynamics and the ITCZ. $J$. Atmos. Sci., 28, (to be published).

Krishnamurti, T.N., and D.P. Baumhefner, 1966: Structure of a tropical disturbance based on solutions of a multi-level baroclinic model. J. Appl. Meteor., 5, 396-406.

Kuo, H.L., 1949: Dynamic instability of twodimensional non-divergent flow in a barotropic atmosphere. J. Meteor., 6, 105-122.

Lipps, F.B., 1970: Barotropic stability and tropical distrubances. Mon. Wea. Rev., 98, 122-131.

Lindzen, R.S., 1967: Planetary waves on beta planes. Mon. Wea. Rev., 95, 441-451.

, and T. Matsuno, 1968: On the nature of large-scale wave disturbances in the equatorial lower stratosphere. J. Meteor. Soc. Japan, 46, 215-221.

Mak, M.K., 1969: Laterally driven stochastic motions in the tropics. J. Atmos. Sci., 26, 41-64.

Manabe, S., and J. Smagorinsky, 1967: Simulated climatology of a general circulation model with a hydrological cycle II. Analysis of the tropical atmosphere. Mon. Wea. Rev. 95, 155-169.

Maruyama, T., 1967: Large-scale disturbances in the equatorial lower stratosphere. J. Meteor. Soc. Japan, 45, 391-408

, 1968a: Time sequence of power spectra of disturbances in the equatorial lower stratosphere in relation to the quasi-biennial oscillation. $J$. Meteor. Soc. Japan, 46, 327-342.

, 1968b: Upward transport of westerly momentum due to large-scale disturbances in the equatorial lower stratosphere. J. Meteor. Soc. Japan, 46, 404-417.

Matsuno, T., 1966: Quasi-geostropic motions in the equatorial area. J. Meteor. Soc. Japan, 44, 25-43.

Nitta, T., 1970a: Statistical study of tropospheric wave disturbances in the tropical Pacific region. $J$. Meteor. Soc. Japan, 48, 47-60.

- 1970b: On the role of transient eddies in the tropical troposphere. J. Meteor. Soc. Japan, 48, 348-359.

- , and M. Yanai, 1969: A note on the barotropic instability of the tropical easterly current. J. Meteor. Soc. Japan, 47, 127-130.

Ogura, Y., 1964: Frictionally controlled, thermally driven circulations in a circular vortex with application to tropical cyclones. J. Atmos. Sci., 21, 610-
621.

Ooyama, K., 1964: A dynamical model for the study of tropical cyclone development. Geofisica Internacional (Mexico), 4, 187-198.

, 1969: Numerical simulation of the life cycle of tropical cyclones. J. Atmos. Soc., 26, 340.

1971: On the stability of wave disturbances in the tropical easterlies. (To be submitted).

Palmer, C.E., 1952: Review of tropical meteorology. Quart. J. Roy. Meteor. Soc., 78, 126-163.

Riehl, H., 1948: On the formation of typhoons. $J$. Meteor., 5, 247-264.

-, 1954: Tropical Meteorology. McGraw Hill Bood Co., 392 p.

- 1969: Some aspects of cumulonimbus convection in relation to tropical weather disturbances. Bull. Amer. Meteor. Soc., 50, 587-595.

Rosenthal, S.L., 1960: Some estimates of the power spectra of large-scale disturbances in low latitudes. J. Meteor., 17, 259-263.

, 1965: Some preliminary theoretical considerations of tropospheric wave motions in equatorial latitudes. Mon. Wea. Rev., 93, 605-612.

Rossby, C.G., and collaborators, 1939: Relation between variations in the intensity of the zonal circulation of the atmosphere and the displacements of the semi-permanent centers of action. $J$. Marine Res., 2, 38-55.

Syōno, S., 1949: Approximate solution of non-linear differential equations of stationary winds in axial symmetric cyclone and anticyclone and its applications. Geophys. Mag., 20, 39-65.

and M. Yamasaki, 1966: Stability of symmetrical motions driven by latent heat released by cumulus convection under the existence of surface friction. J. Meteor. Soc. Japan, 44, 353375.

Wallace, J.M. and C.P. Chang, 1969: Spectrum analysis of large-scale wave disturbances in the tropical lower troposphere. J. Atmos. Sci., 26. 1010-1025.

Yamasaki, M., 1968a: Numerical simulation of tropical cyclone development with the use of primitive equations. J. Meteor. Soc. Japan, 46, 178-201.

, 1968b: A tropical cyclone model with parameterized vertical partition of released latent heat. J. Meteor. Soc. Japan, 46, 202-214.

, 1968c: A detailed analysis of a tropical cyclone simulated with a 13-layer model. Pap. Meteor. Geophys., 19, 559-595.

, 1969: Large-scale disturbances in the conditionally unstable atmosphere in low latitudes. Pap. Meteor. Geophys., 20, 289-336.

, 1971: Frictional convergence in Rossby waves in low latitudes. Syōno Memorial Volume (to be published). 
Yamasaki, M. and M. Wada, 1971: Barotropic instability of an easterly zonal current. (to be submitted).

Yanai, M., 1961: A detailed analysis of typhoon formation. J. Meteor. Soc. Japan, 39, 187-214. , 1963: A preliminary survey of large-scale disturbances over the tropical Pacific region. Geofisica Internacional (Mexico), 3, 73-84.

- 1968: Evolution of a tropical disturbance in the Caribbean Sea region. J. Meteor. Soc. Japan, 46, 86-109.

, and Y. Hayashi, 1969: Large-scale equatointo the lower stratosphere. J. Meteor. Soc. Japan, 47, 167-182.

, and T. Maruyama, 1966: Stratospheric wave disturbances propagating over the equatorial Pacific. J. Meteor. Soc. Japan, 44, 291-294.

- , and M. Murakami, 1970a: A further study of tropical wave disturbances by the use of spectrum analysis. J. Meteor. Soc. Japan, 48, 186197.

- and M. Murakami, 1970b: Spectrum analysis of symmetric and antisymmetric equatorial waves. J. Meteor. Soc. Japan, 48, 331-347. , and T. Nitta, 1967: Computation of vertical motion and vorticity budget in a Caribbean easterly wave. J. Meteor. Soc. Japan, 45, 444-466. , T. Maruyama, T. Nitta, and Y. Hayashi, 1968: Power spectra of large-scale disturbances over the tropical Pacific. J. Meteor. Soc. Japan, 46, 308-323.

\section{条件付不安定な熱帯大気モデルにおける波動擾乱}

$$
\begin{gathered}
山 \text { 岬 正 紀 } \\
\text { ニューヨーク大学 }
\end{gathered}
$$

前論文 (Yamasaki, 1969；Ooyama，1971) の続さとして，球座標プリミティブ方程式を用いて，条件付不安定な 熱帯大気モデルに拈ける波動擾乱の性質を調べた。対流による潜熱の放出の効果は，前回と同様に，Ooyama（1964） の方法でとり入れた.

一般流や地表摩擦や潜熱の放出がないときには，Haurwitz（1940b） が論じた非発散ロスビー波と，Matsuno (1966) が論じた発散ロスビー波（混合ロスビ一重力波を含む）, 重力波，ケルビン波が方程式の解として存在する. 非発散ロスビー波は, 地表摩擦と一般流の垂直シアとによって生ずる上昇流に伴った潜熱の放出によって不安定化す ることが示される。この不安定波の東西波長は，一般流の垂直シア一の増大と共に $2,000 \mathrm{~km}$ から $6,000 \mathrm{~km}$ 位の 值をとる. 南北モードの最も低い波 $(n=0)$ は, Palmer (1952) によって記述された赤道偏東風波や, Chang et al. （1970）によって解析された偏東風波とよい対応を示すように思われる. この $n=0$ モードでは, コリオリのパラメ ーターの值と波の振動数とが一致する緯度付近に摩擦収束の最大があらわれ (Holton et al., 1971; Yamasaki, 1971), 従って, このモードの不安定性は, この緯度付近の摩擦収束に伴ら潜熱の放出に強く依存している.

他の種類の不安定波の性質についても簡単にふれる. 